\title{
A systematic review of cognitive behavior therapy and dialectical behavior therapy for adolescent eating disorders
}

\author{
Emily N. Vogel ${ }^{1,3^{*}} \mathbb{D}$, Simar Singh $\mathrm{h}^{2,3}$ and Erin C. Accurso ${ }^{3}$
}

\begin{abstract}
Background: Eating disorders have serious psychological and physical consequences. Current evidence-based treatments for adolescents with eating disorders have modest effects, underscoring the need to improve current treatment approaches. Cognitive behavior therapy (CBT) and dialectical behavior therapy (DBT) have been proposed as alternative treatment options, with burgeoning research in this area. This review aims to summarize and critically analyze the current literature on the feasibility, acceptability, effectiveness, and efficacy of CBT and DBT for adolescent eating disorders, and then proposes areas of future research.
\end{abstract}

Methods: PsycINFO and PubMed were searched using the Preferred Reporting Items for Systematic Review and Meta-Analyses guidelines to identify studies examining the feasibility, acceptability, effectiveness and/or efficacy of CBT or DBT for adolescent eating disorders.

Results: Eligible studies ( $N=50 ; \mathrm{CBT}: n=40, \mathrm{DBT}: n=10$ ) indicated that both treatments are reasonably feasible, acceptable, and possibly effective for adolescent eating disorders across diagnoses and levels of care, though efficacy trials are lacking.

Conclusions: CBT and DBT demonstrate promise as alternatives to family-based approaches for adolescent eating disorders. Adequately powered trials to establish the effectiveness and efficacy of CBT and DBT are needed, particularly ones that compare these treatments against other leading approaches.

Plain English summary: Despite high rates of relapse and likelihood for severe and enduring illness, there is a dearth of evidence-based treatment options for adolescents with eating disorders. Potentially viable but less well-studied treatments for adolescents with eating disorders include cognitive behavior therapy (CBT) and dialectical behavior therapy (DBT). This systematic review of CBT and DBT for adolescent eating disorders focuses on feasibility (i.e., how easy it was to implement the treatment), acceptability (i.e., how well the intervention was received by patients and therapists), effectiveness (i.e., how well the intervention performed under routine, real-world circumstances), and efficacy (i.e., how well the intervention performed in highly-controlled research settings). This review concludes that research supports the feasibility and acceptability of these approaches, as well as preliminary evidence of their effectiveness. However, the field is lacking studies that systematically compare CBT and DBT to other evidence-based approaches. Recommendations to advance research on CBT and DBT for adolescent eating disorders are provided, including a call for efficacy studies that clarify their performance compared to other leading approaches.

Keywords: Eating disorders, Cognitive behavior therapy, Dialectical behavior therapy, Adolescent

*Correspondence: evogel@paloaltou.edu

${ }^{1}$ PGSP-Stanford PsyD Consortium, Palo Alto University, Palo Alto, CA, USA

Full list of author information is available at the end of the article permits use, sharing, adaptation, distribution and reproduction in any medium or format, as long as you give appropriate credit to the original author(s) and the source, provide a link to the Creative Commons licence, and indicate if changes were made. The images or other third party material in this article are included in the article's Creative Commons licence, unless indicated otherwise in a credit line to the material. If material is not included in the article's Creative Commons licence and your intended use is not permitted by statutory regulation or exceeds the permitted use, you will need to obtain permission directly from the copyright holder. To view a copy of this licence, visit http://creativecommons.org/licenses/by/4.0/. The Creative Commons Public Domain Dedication waiver (http://creativeco mmons.org/publicdomain/zero/1.0/) applies to the data made available in this article, unless otherwise stated in a credit line to the data. 


\section{Background}

Eating disorders are associated with high rates of cooccurring psychiatric disorders $[1,2]$ and serious medical risks including death $[3,4]$. In adolescents, some of the medical complications resulting from malnutrition (e.g., osteoporosis, growth arrest) may be irreversible if weight restoration is not attained [5]. Existing evidencebased treatments for youth with eating disorders produce modest effects at best. Indeed, over half of adolescents who receive the treatment most supported by research evidence-family-based treatment (FBT) for anorexia nervosa (AN) [6]-are still not recovered one year after completing treatment $[7,8]$. Furthermore, FBT is not feasible or clinically indicated for all youth (e.g., caregiver(s) unavailable or not willing to participate, prior and/or current abuse in the home, co-occurring suicidality and emotion dysregulation that is better managed within a dialectical behavior therapy [DBT] framework). Therefore, increasing the availability of other treatments and improving treatment outcomes overall is critical.

Cognitive behavior therapy (CBT) and DBT-a thirdwave $\mathrm{CBT}$-have been proposed as alternative treatments that may be appropriate when FBT is not feasible. CBT is widely considered the first-line of treatment for adults with bulimia nervosa (BN) and binge eating disorder (BED) [9], and has been "enhanced" to target transdiagnostic eating disorders in adults (CBT-E: [10]) and more recently adolescents [11]. CBT may be suitable for adolescents with eating disorders given its focus on mechanisms hypothesized to maintain the disorder (e.g., overvaluation of weight and shape; [12]), efficacy for other disorders in adolescents (e.g., depression and anxiety; $[13,14]$ ), and developmental appropriateness for adolescents (e.g., collaborative style and techniques support motivation while respecting adolescents' developing autonomy; [15]).

Meanwhile, DBT was originally developed for adults with borderline personality disorder [16]. It incorporates both cognitive behavioral and mindfulness-based strategies in order to increase interpersonal effectiveness, improve emotion regulation, and build distress tolerance. DBT has since been applied to adolescent populations with borderline personality disorder features $[17$, $18]$ and adults with other presenting concerns $[19,20]$, and may be particularly appropriate for adolescents whose eating disorder psychopathology is perpetuated by mechanisms targeted in DBT, including emotion regulation (i.e., inhibited emotion expression, more typical in AN; emotion intensity and dysregulation, more typical in BN and BED; [21]). Moreover, DBT's framework is designed to focus on multiple target behaviors simultaneously, which is often crucial for adolescents with eating disorders with co-occurring disorders and related target symptoms (e.g., suicidal ideation, non-suicidal self-injury, substance abuse). The ability to focus on multiple problem areas in an integrated and structured manner-consistent with high fidelity to the treatment model-is a unique asset of DBT, in contrast to alternative, evidencebased frameworks (e.g., CBT, FBT) that require almost exclusive focus on the eating disorder, particularly early in treatment.

The present review aims to add to the literature by providing an update on second- and third-wave CBT approaches for adolescents across eating disorder diagnoses, inclusive of non-randomized study designs (i.e., case series, case studies, and naturalistic study designs). To date, there has only been one systematic review that included second- and third-wave CBTs for adolescent eating disorders, which focused exclusively on randomized controlled trials for adolescent AN or BN [22]. Data from non-randomized study designs provide important information on treatment feasibility, acceptability and effectiveness within real-world settings. In contrast, highly controlled research designs frequently fail to consider factors that impact real-world implementation (e.g., patient characteristics such as co-occurring disorders, or clinician characteristics such as level of training), creating a gap between research and clinical conditions that limit their practical value [23].

With the ultimate goal of supporting clinicians to make appropriate treatment real-world clinical decisions, studies that examine treatments in usual care settings are crucial. Therefore, this review includes studies investigating treatments with multiple components (e.g., FBT integrated with DBT skills), rather than including only studies of "pure" CBT or DBT. Although multiple thirdwave CBTs have been proposed for eating disorders (e.g., acceptance and commitment therapy), we focus on DBT since it is the most widely studied to-date [24]. Given the diversity in diagnosis, treatment type, treatment setting, study methodology, and outcome measurement, a systematic review was deemed most appropriate to summarize the available data, rather than a meta-analysis, which would have yielded an effect estimate that would have been difficult to interpret given the heterogeneity of the data. Overall, this review summarizes and critically analyzes the literature on CBT and DBT for adolescent eating disorders, with the objective of clarifying current knowledge about the feasibility, acceptability, effectiveness, and efficacy of these approaches, and providing recommendations for future research.

\section{Methods}

PsycINFO (Ovid) and PubMed were searched using the Preferred Reporting Items for Systematic Review and Meta-Analyses guidelines [25]. The following search 
algorithms were used, inclusive of all papers published through December 2020: [(cognitive behavior therapy OR CBT) AND (adolesc*) AND (eating disorder)], and [(dialectical behavior therapy OR DBT) AND (adolesc*) AND (eating disorder)]. The first author screened CBT titles and abstracts for relevance, and the second author screened DBT titles and articles and abstracts for relevance. Articles deemed relevant based on title and abstract were then reviewed. Each author replicated and verified the other author's search, to control for bias. Discrepancies were discussed and resolved in consultation with the senior author. Eligible articles (1) assessed the feasibility, acceptability, effectiveness and/or efficacy of CBT, DBT, or any other psychological treatment based at least in part on CBT or DBT (2) in adolescents with eating disorders (3) and were published in peer-reviewed, academic journals (4) in the English language. Studies that assessed interventions in a partial hospitalization setting ( $n=2$ CBT studies: one for AN and one for avoidant/restrictive food intake disorder, $n=3$ DBT studies: one for restrictive eating disorders and two for transdiagnostic eating disorders) were excluded because there were too few studies by treatment type and diagnostic category within this setting type to draw meaningful conclusions.

Variables extracted from studies included sample characteristics (sample size, mean age, diagnoses); treatment attrition rate; treatment characteristics (treatment type, setting, length); study follow-up time-points; variables related to eating disorder psychopathology, behavior, and weight restoration; additional primary outcomes relevant to the effectiveness or efficacy of the intervention; and any outcome variables related to the feasibility or acceptability of the intervention. The study results are grouped by intervention type (CBT, DBT) and level of care (e.g., outpatient, inpatient) (see Tables 1,2), then organized by eating disorder diagnosis in the results section below. Given the inclusion of non-randomized designs, our conclusions are based on a qualitative synthesis of the data.

Risk of bias for each study was evaluated using study quality assessment tools recommended in a recent review [26], published by the National Institute of Health [27] and the Joanna Briggs Institute [28]. Cohort studies (i.e., longitudinal studies sampled based on exposure to the intervention rather than outcome; [29]) with no control group were rated using the NIH Quality Assessment Tool for Before-After (Pre-Post) Studies with No Control Group. Randomized controlled trials were rated using the NIH Quality Assessment of Controlled Intervention Studies. The NIH Quality Assessment Tool for Observational Cohort and Cross-Sectional Studies, and the Joanna Briggs Institute Critical Appraisal Checklist for Case Reports were used for these respective study designs (see
Tables 1, 2 for study design type for each paper). The first and second authors rated each study independently, and resolved discrepancies via discussion of individual checklist items, and in consultation with the senior author. The $\mathrm{NIH}$ quality assessment tools evaluate the internal validity of studies with consideration of individual checklist items and an overall rating of "good," "fair," or "poor"; a higher rating indicates lower risk of bias based on the study design or execution, while a lower rating indicates higher risk of bias. The Joanna Briggs Institute Critical Appraisal Checklist for Case Reports provides an overall rating of "include," "exclude" or "seek further information" based on consideration of eight survey items. Two case reports meeting eligibility criteria received an "exclude" quality appraisal rating, and were excluded from the review. Overall ratings for each study are reported in Tables 1 and 2.

\section{Results}

The PsycINFO search yielded 209 results for CBT studies and 38 results for DBT studies. The PubMed search yielded 680 results for CBT studies and 48 results for DBT studies. Fifty articles (CBT: $n=40$, DBT: $n=10)$ met eligibility criteria and were included in this review (see Fig. 1). Tables 1 and 2 provide a complete list of the variables extracted and a summary of relevant findings for each study, including outcome measures.

\section{CBT for adolescent eating disorders Outpatient settings}

Thirty articles examined the feasibility, acceptability, effectiveness, and/or efficacy of outpatient CBT for adolescents, representing 24 different studies (one study produced one secondary analysis article, one study produced two secondary analysis articles, and another produced three secondary analysis articles). Excluding articles that reported data from the same study $(n=6)$, these studies reported outcomes for adolescents with $\mathrm{AN}(n=11), \mathrm{BN}$ $(n=10)$, BED $(n=1)$, or transdiagnostic eating disorders $(n=4)$ using randomized controlled trial designs $(n=7)$, pre-post designs with no control group (i.e., cohort studies; $n=11)$, an observational cross-sectional design $(n=1)$, and case studies $(n=5)$. About one-half of the original studies $(n=13,54 \%)$ reported follow-up data. The majority of studies $(n=19,76 \%)$ evaluated individual CBT, a subset of which $(n=6,32 \%)$ evaluated CBTE. Four studies integrated CBT with at least one other treatment type (e.g., FBT, parental counseling, and/or or dietary therapy), and two evaluated group CBT. Most studies $(n=18,72 \%)$ reported some form of parental involvement, though this varied greatly from peripheral, "as-needed" involvement (e.g., recruiting parents to help with meal planning; [30]), to formal parent sessions at 


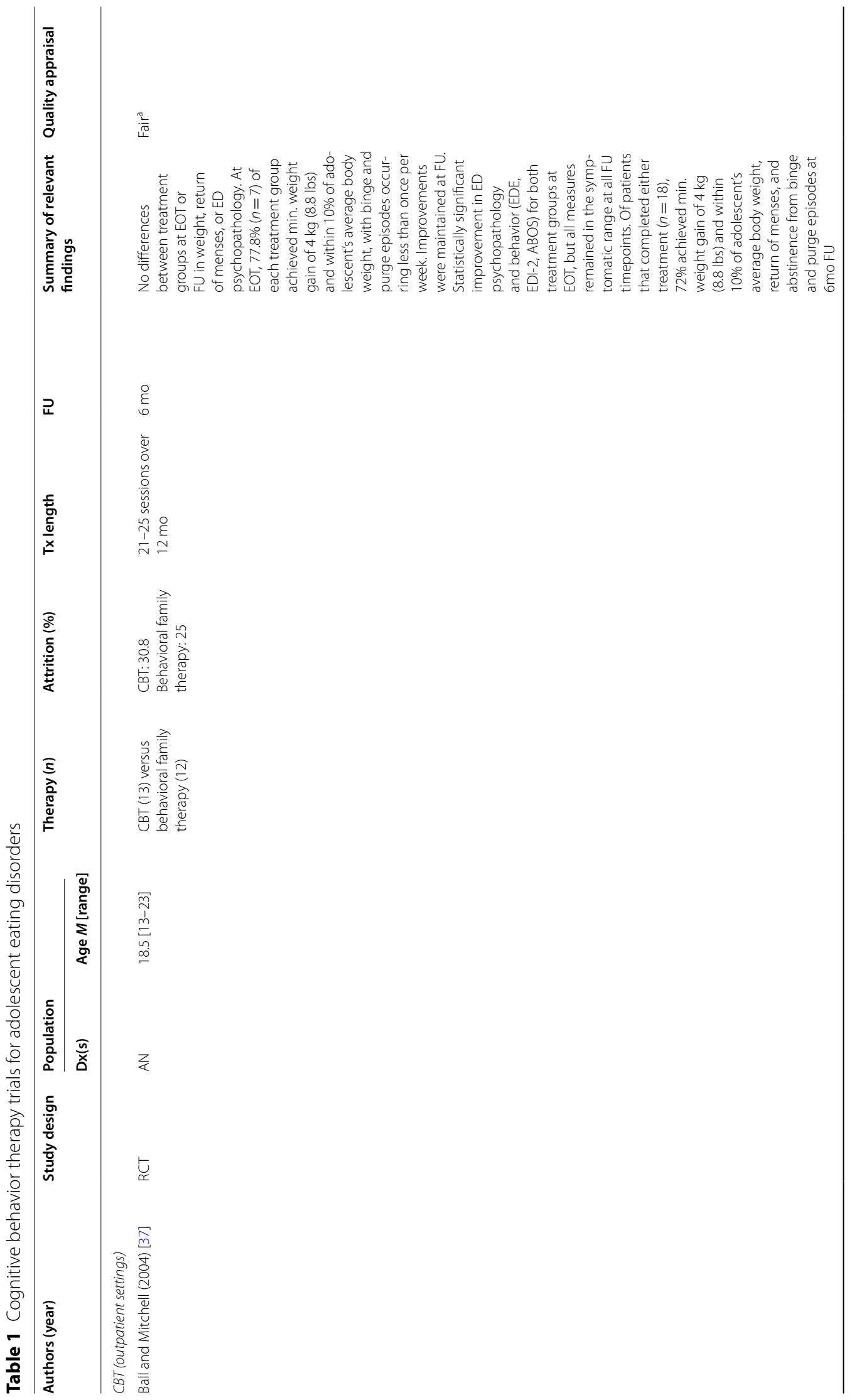




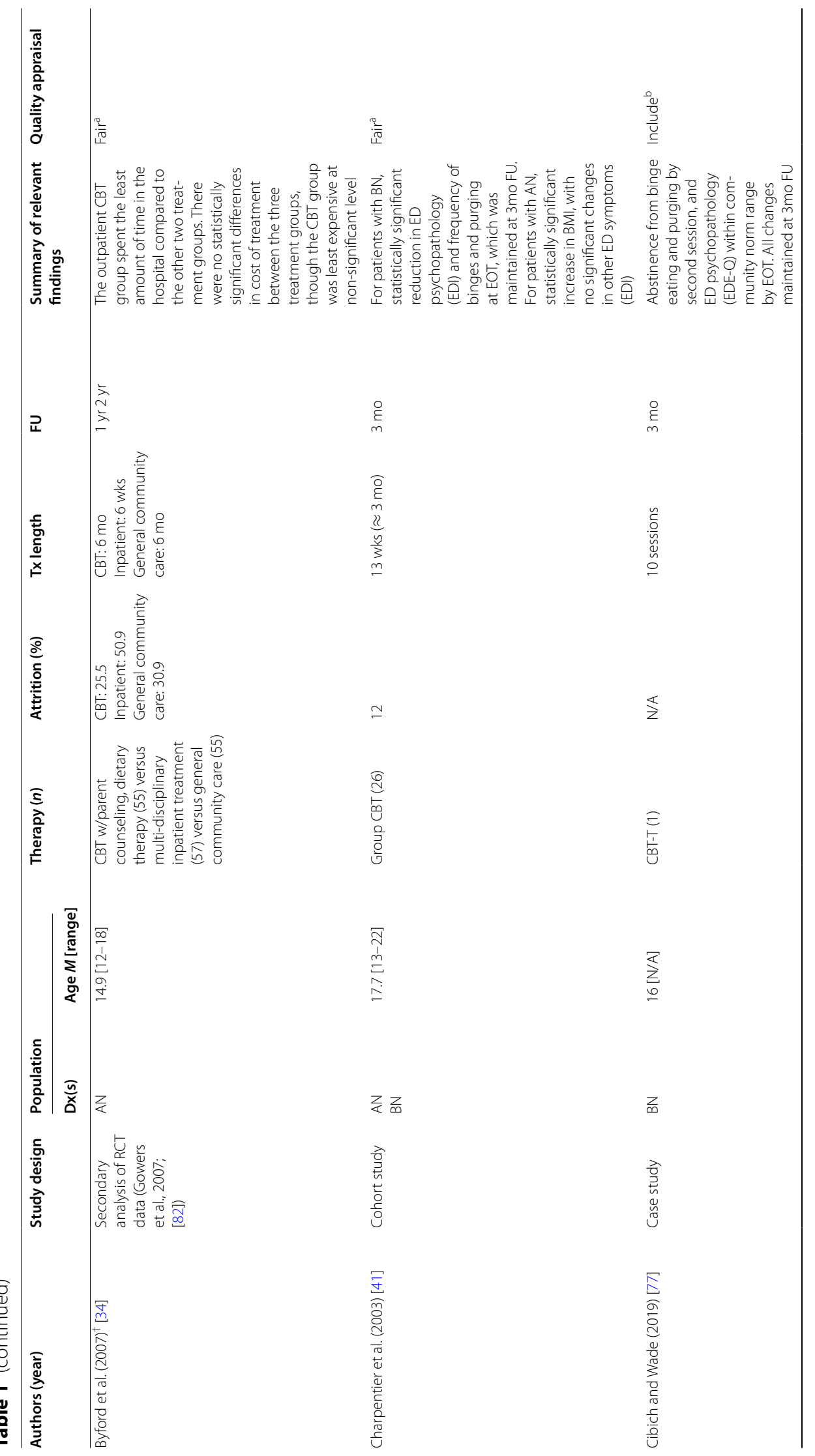




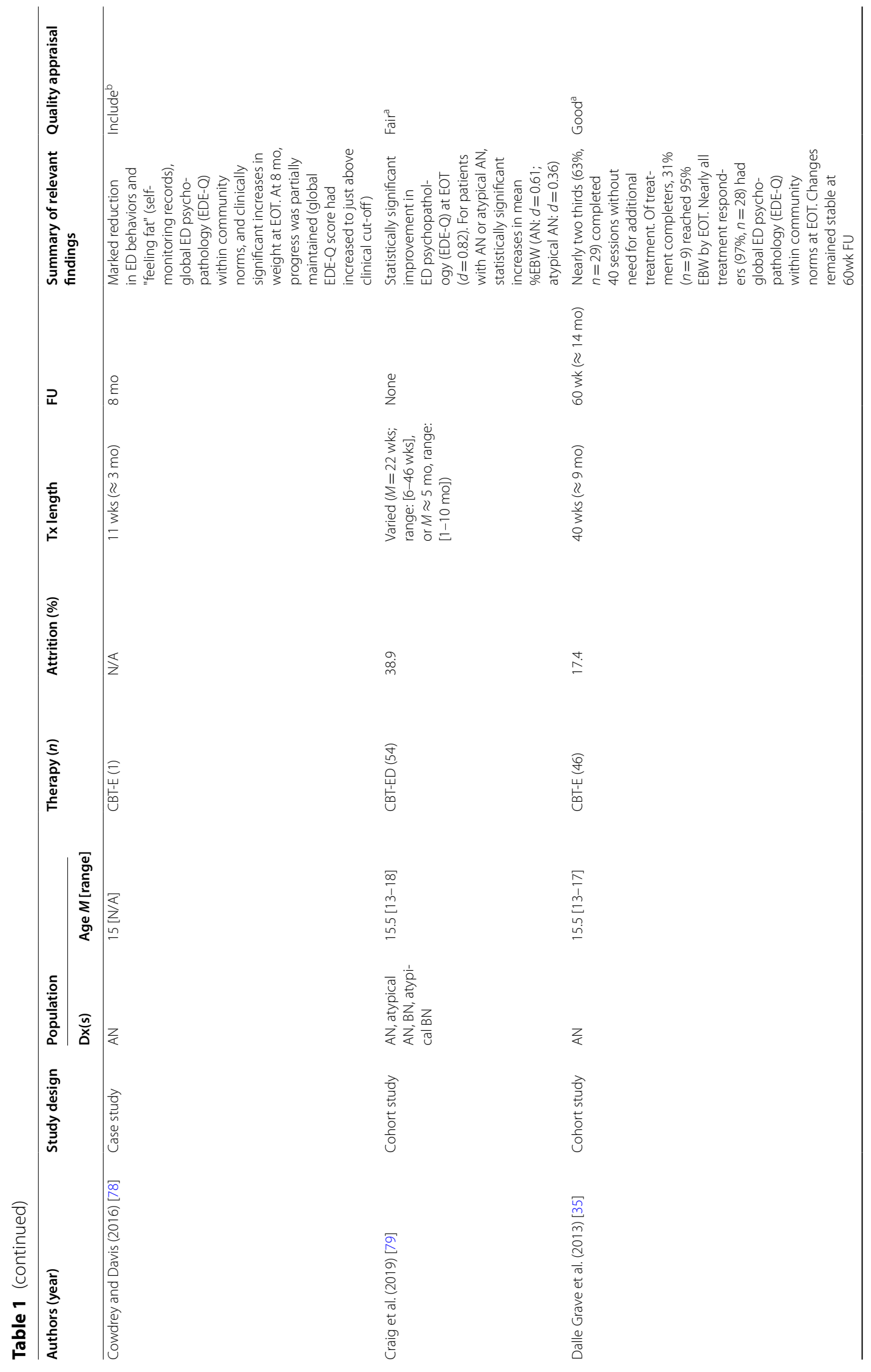




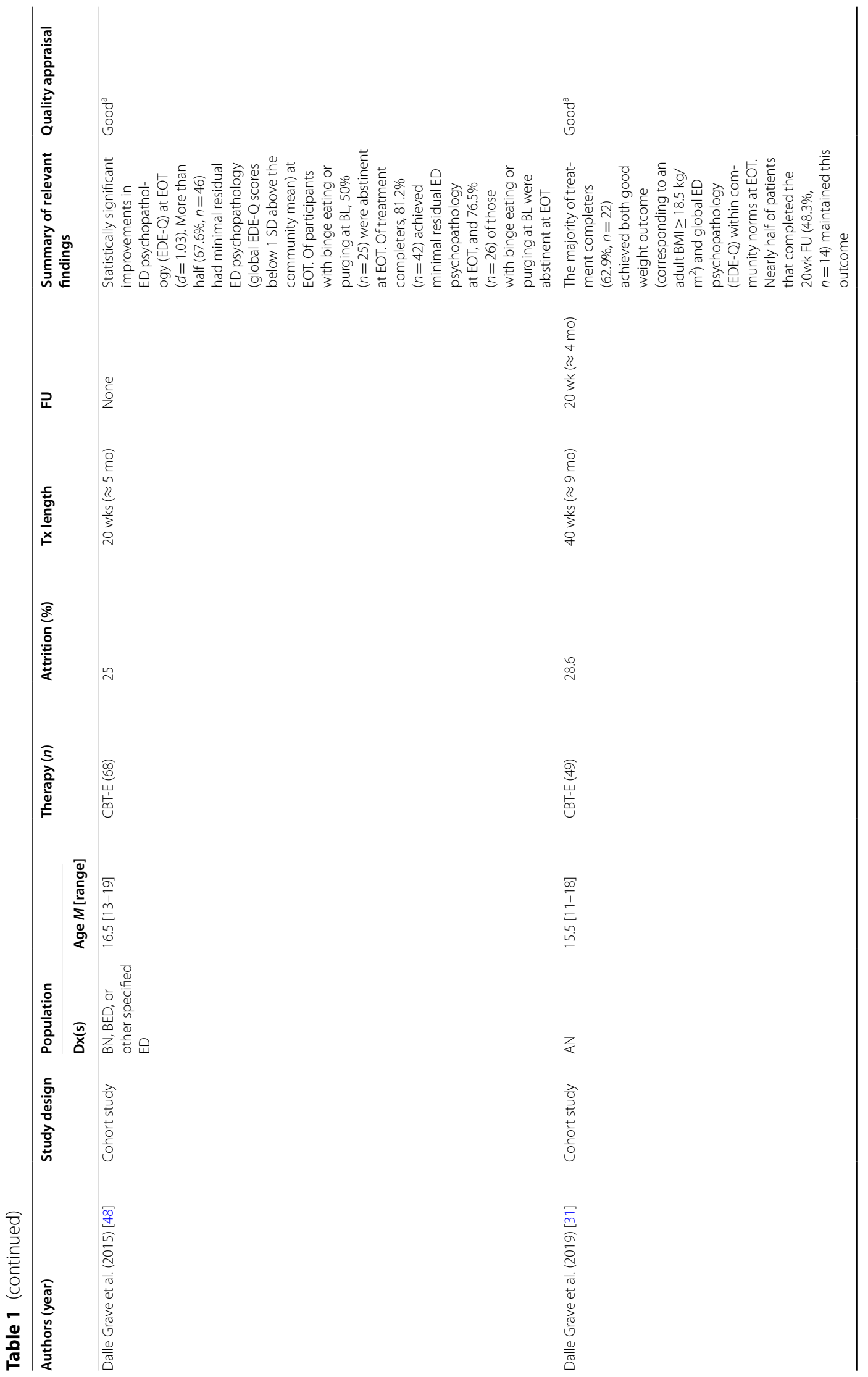




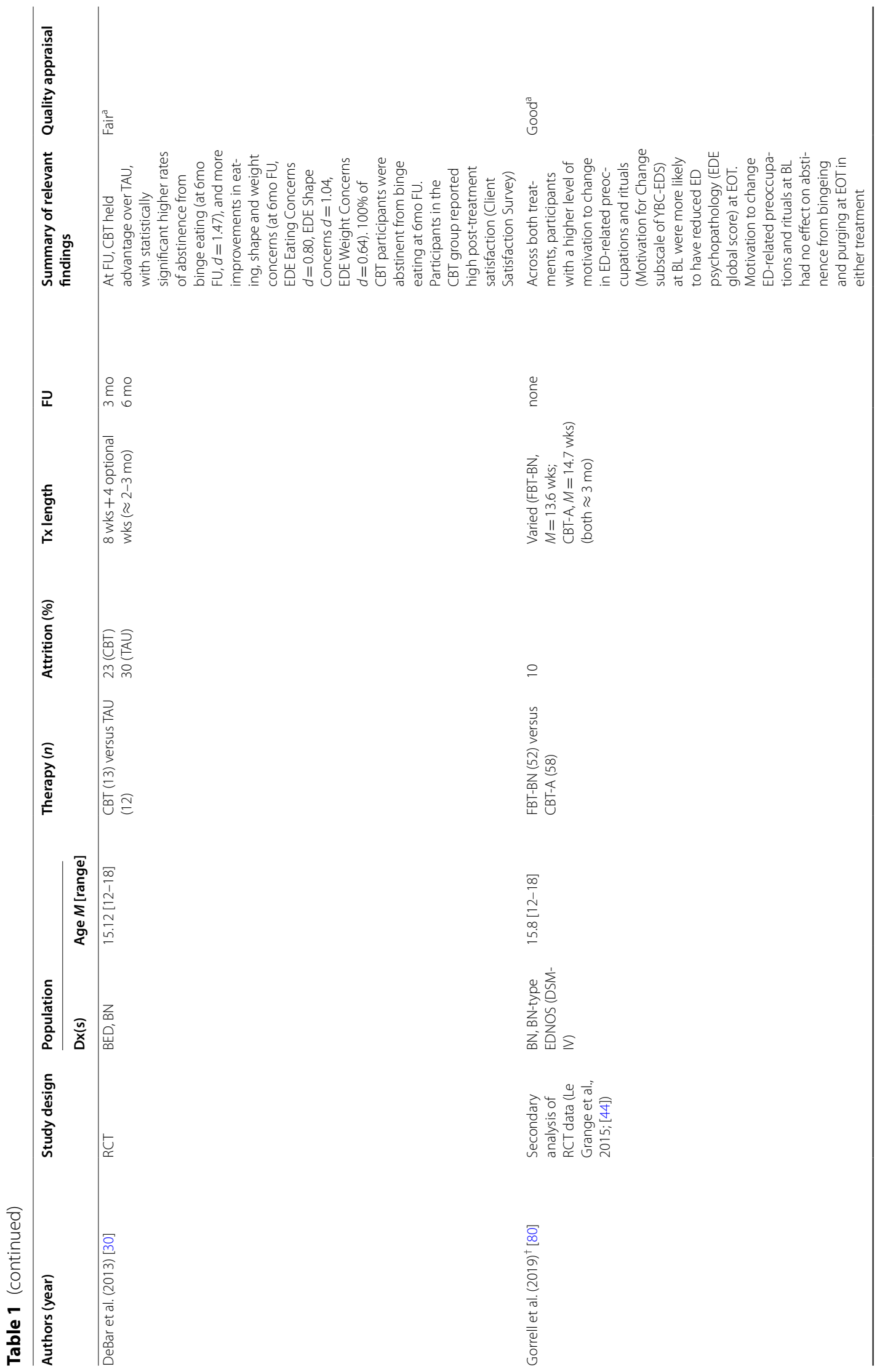




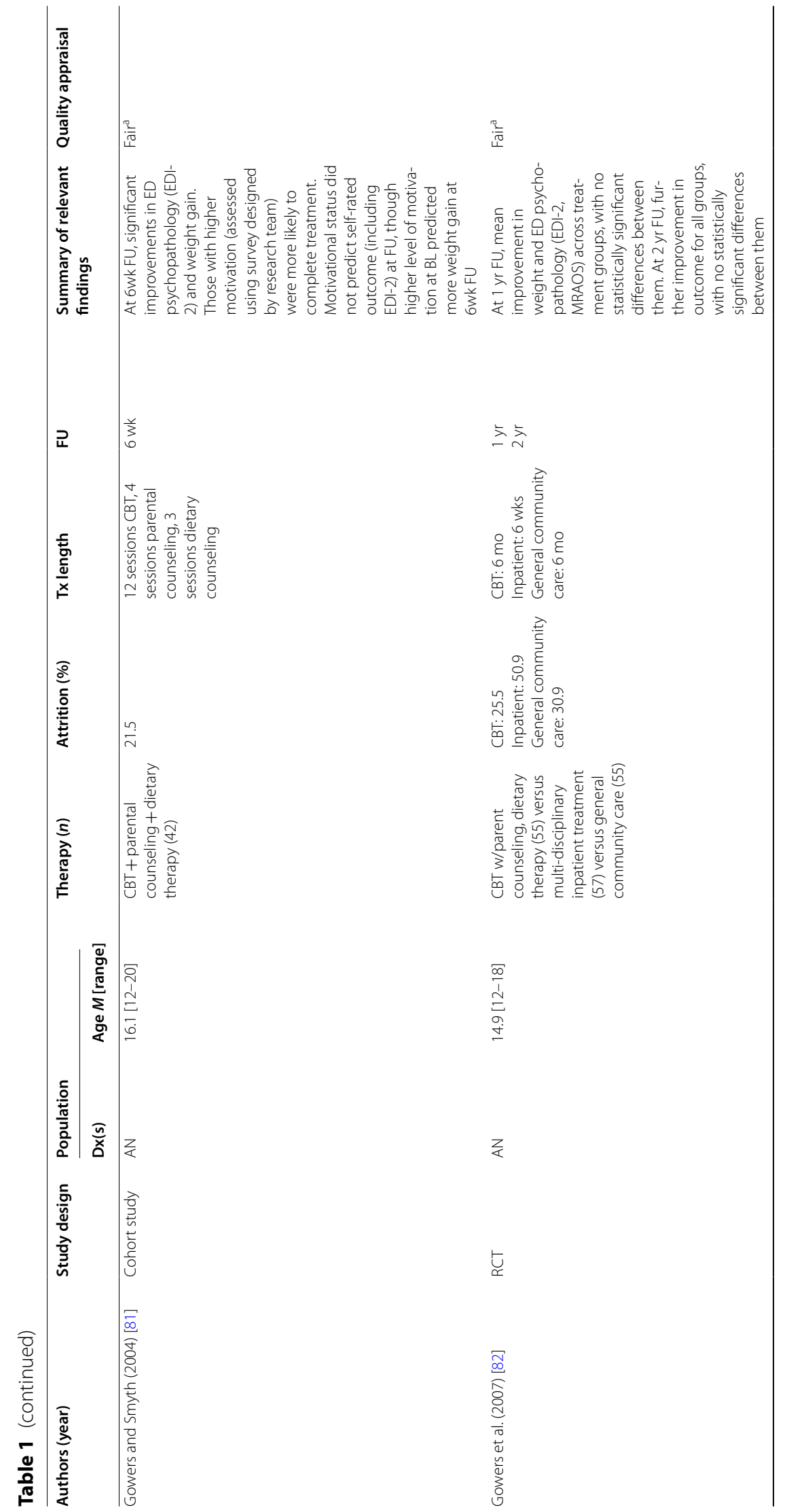




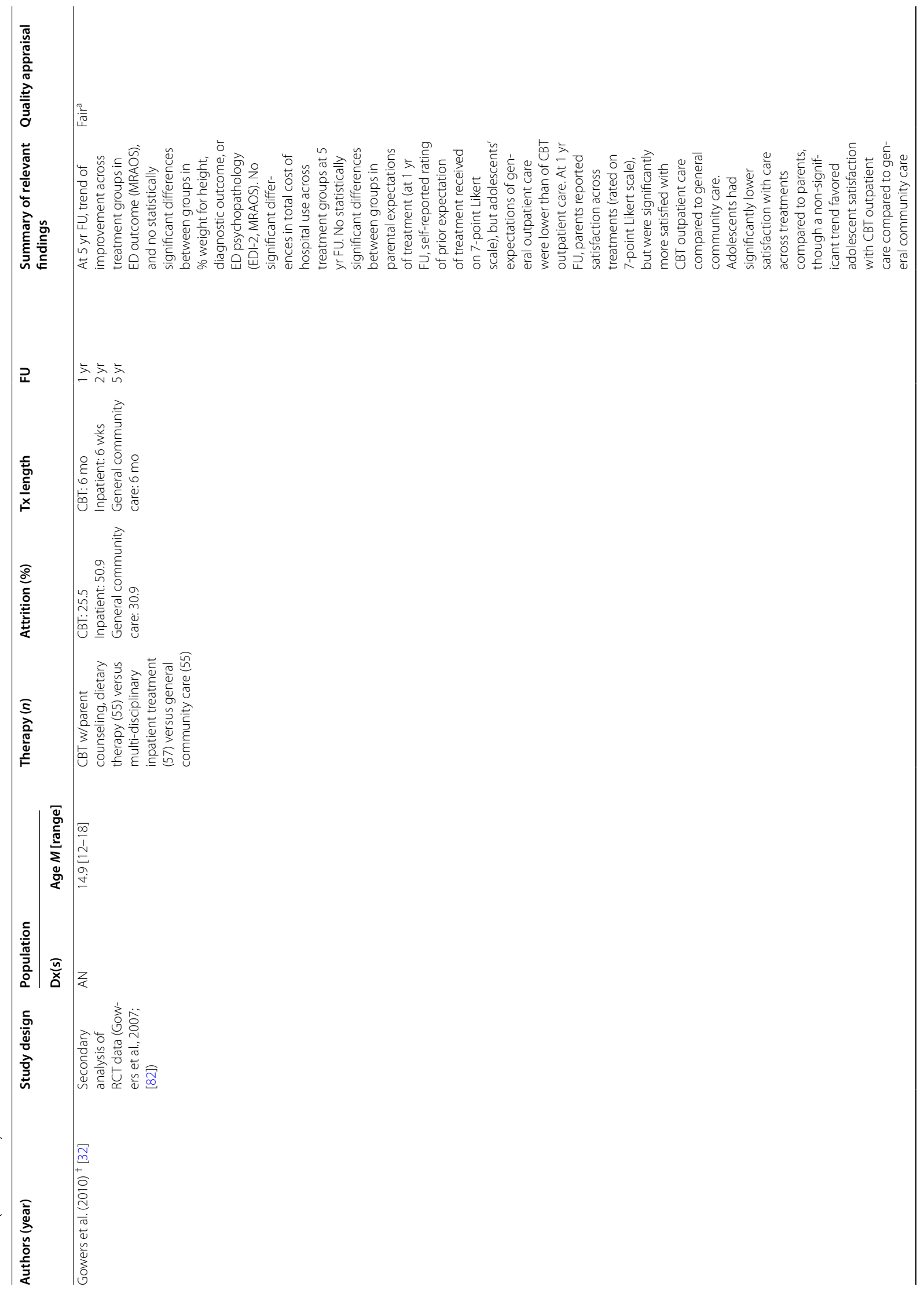




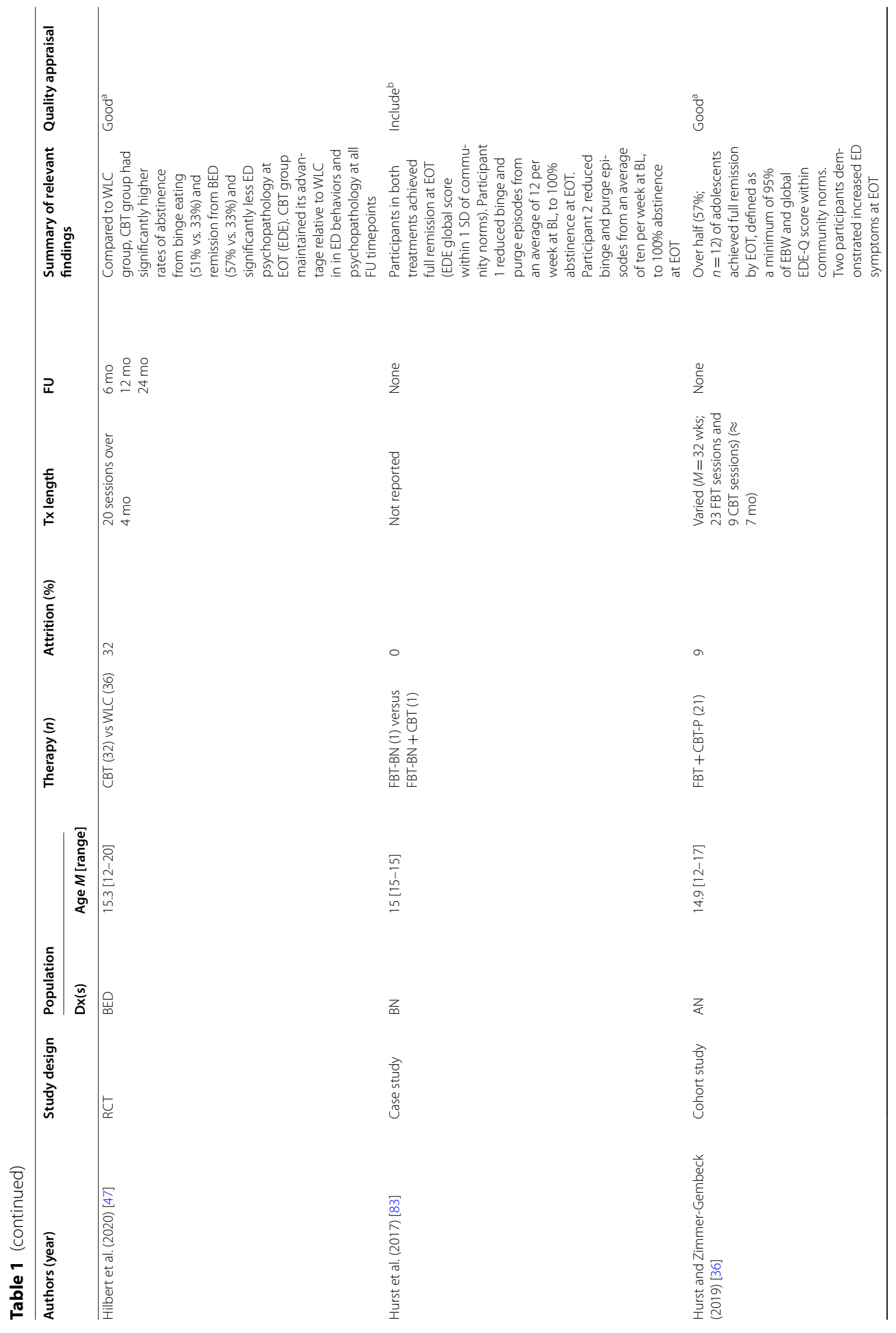




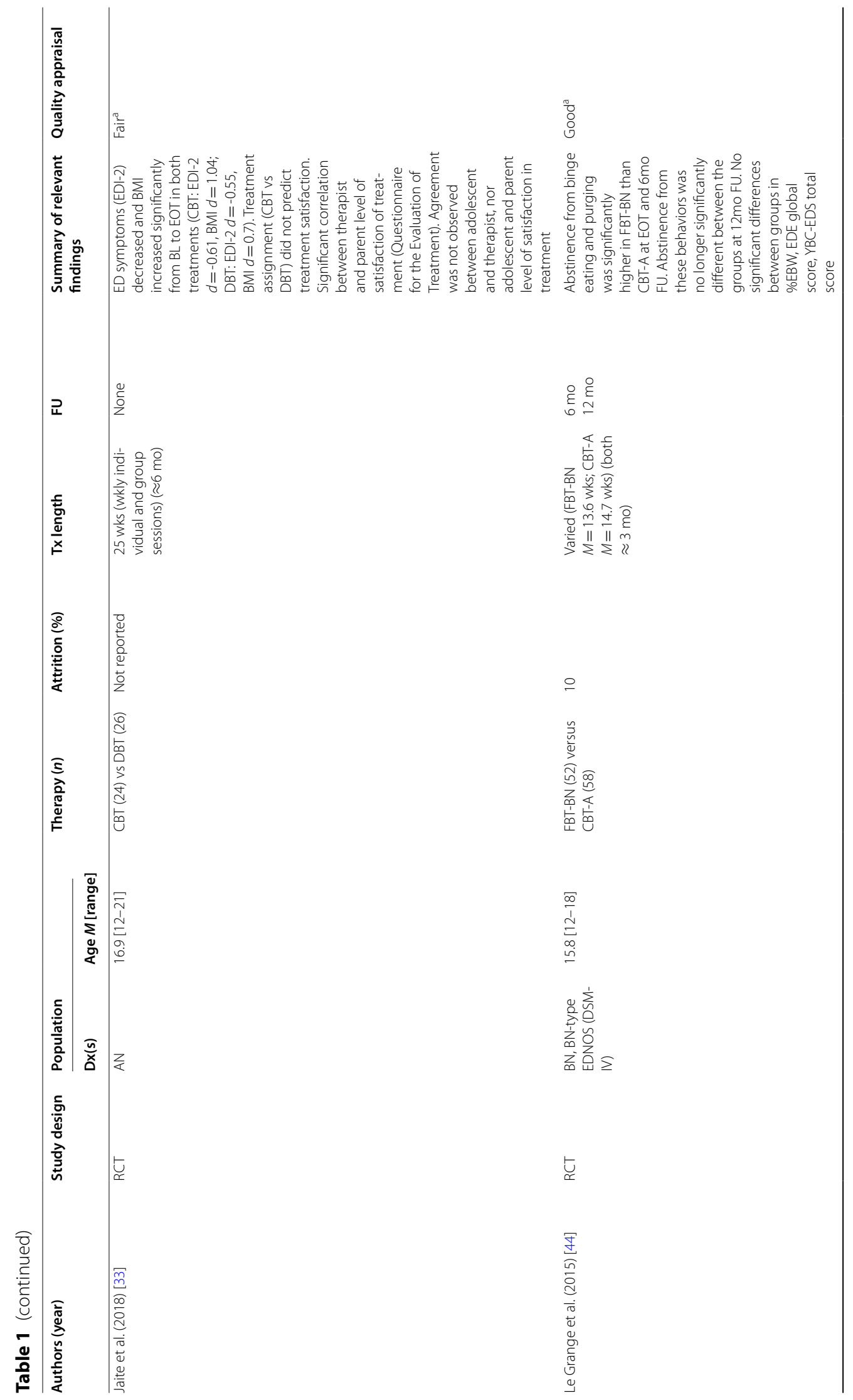




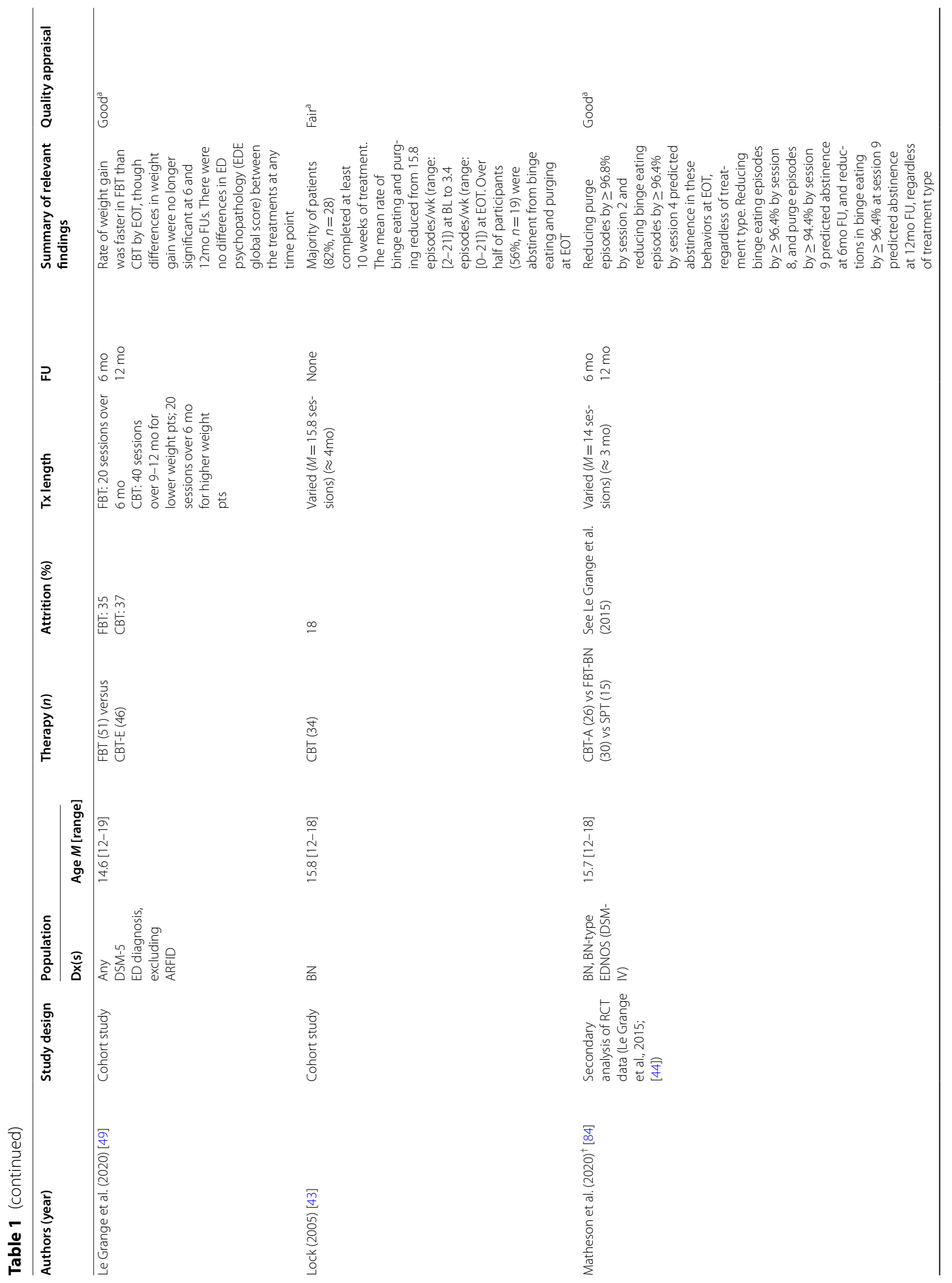




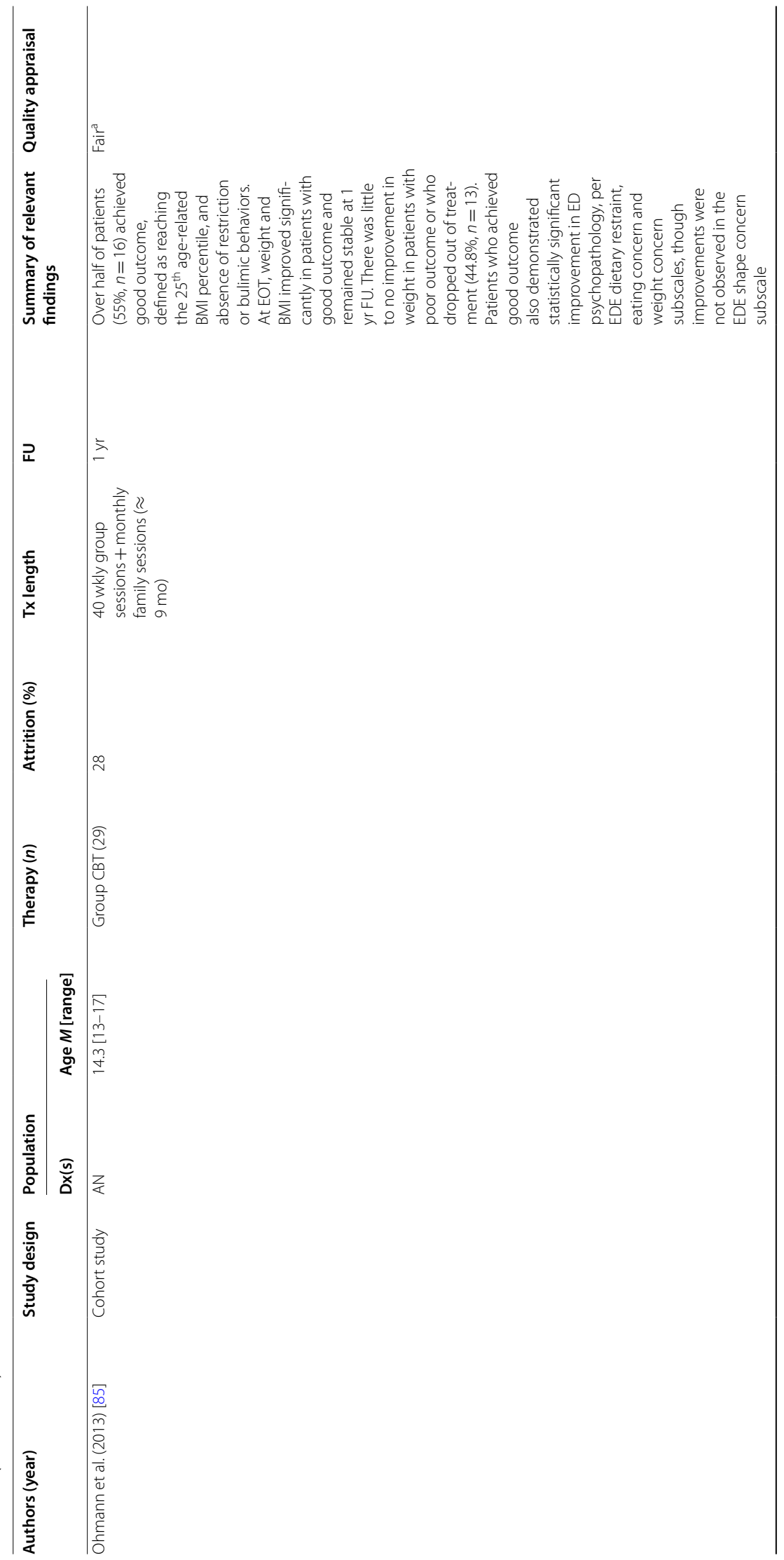




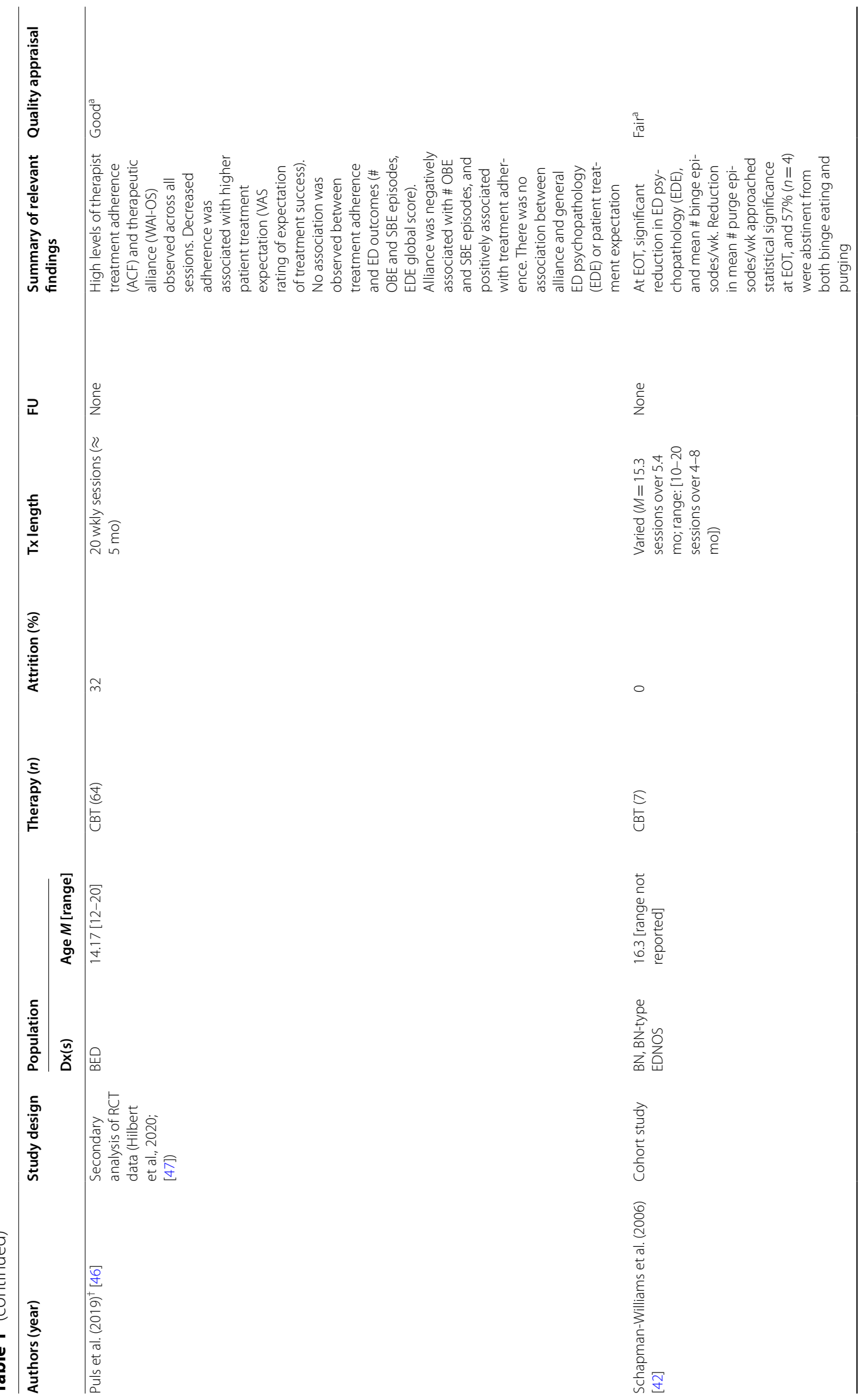




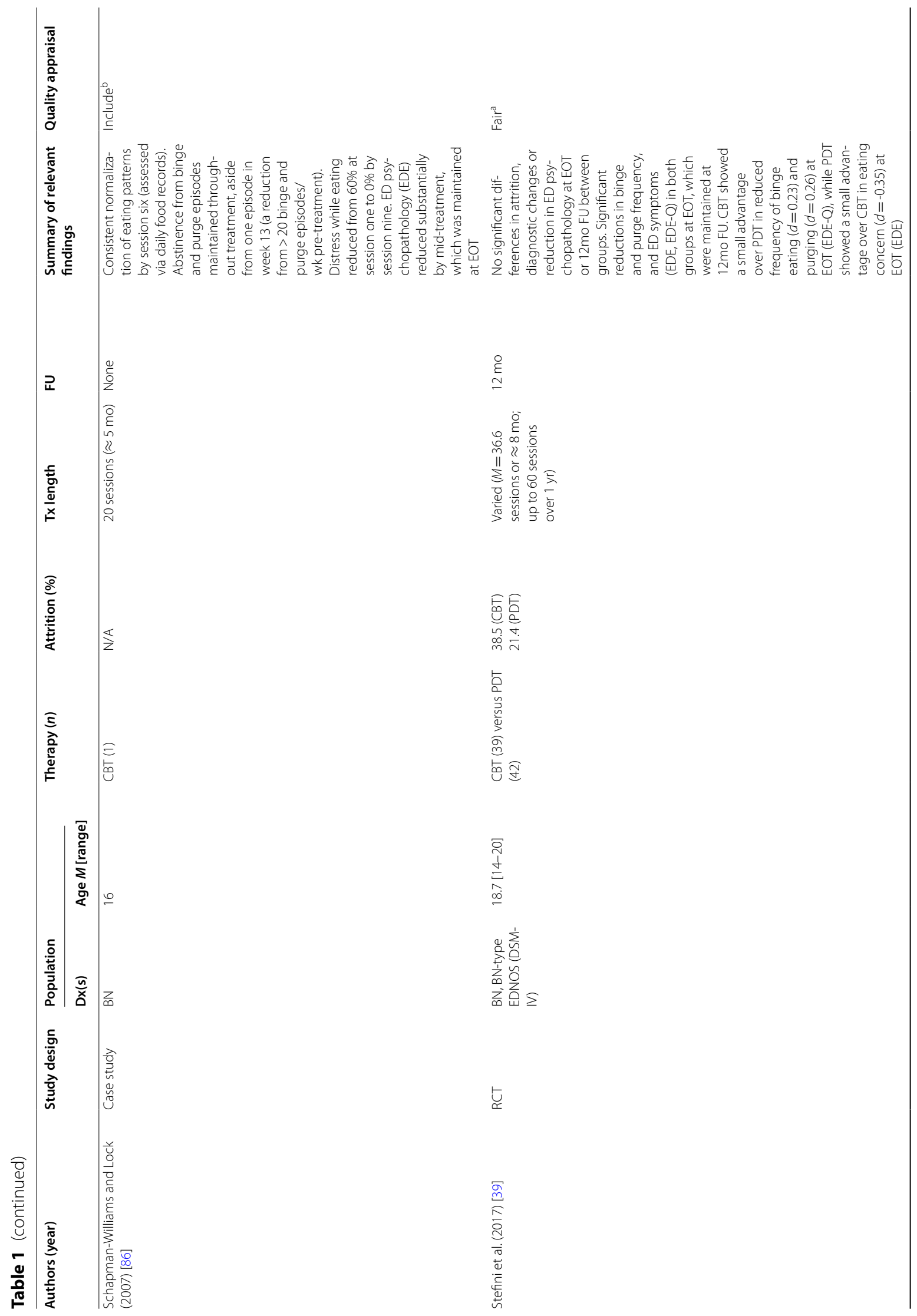




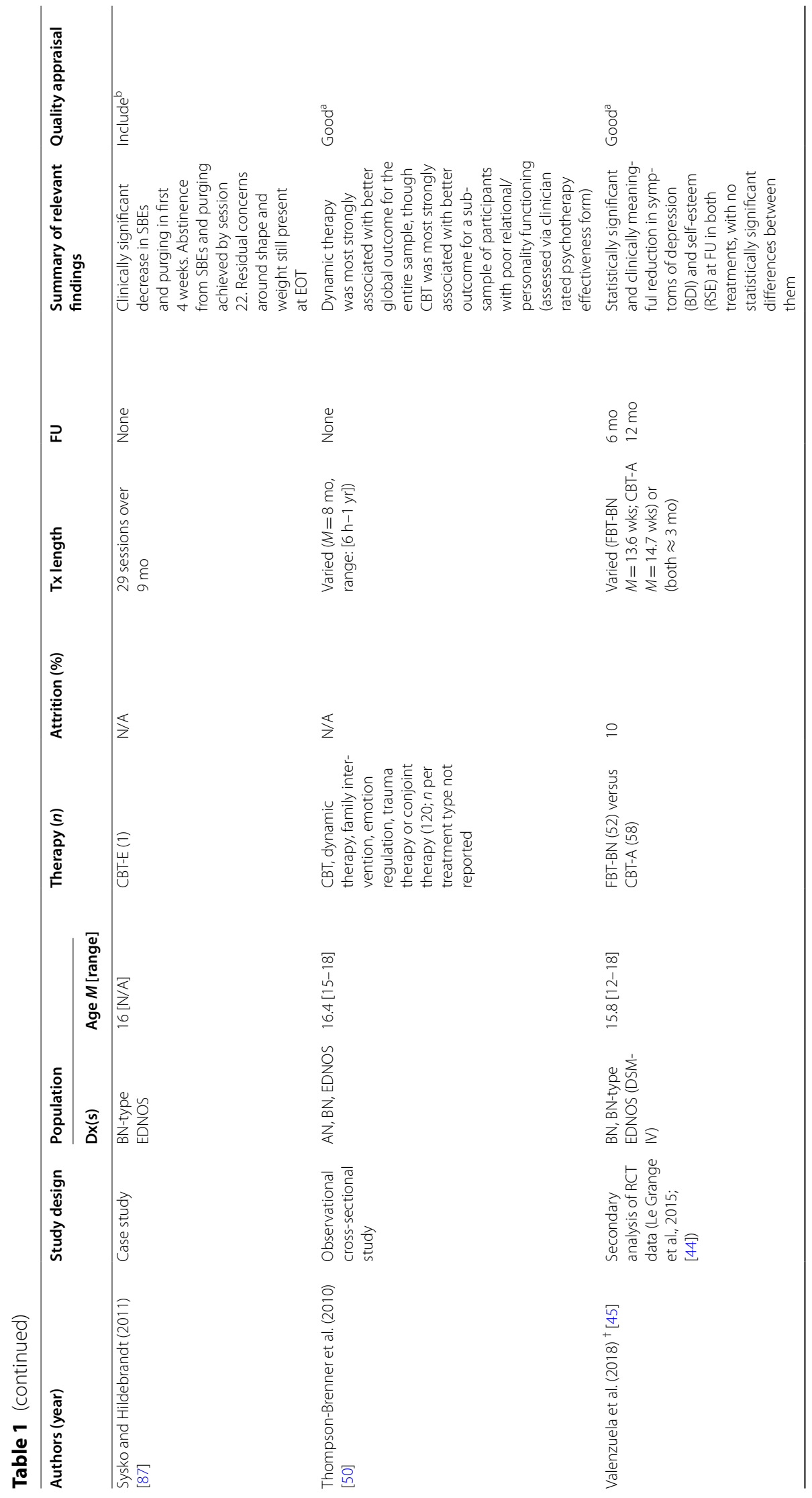




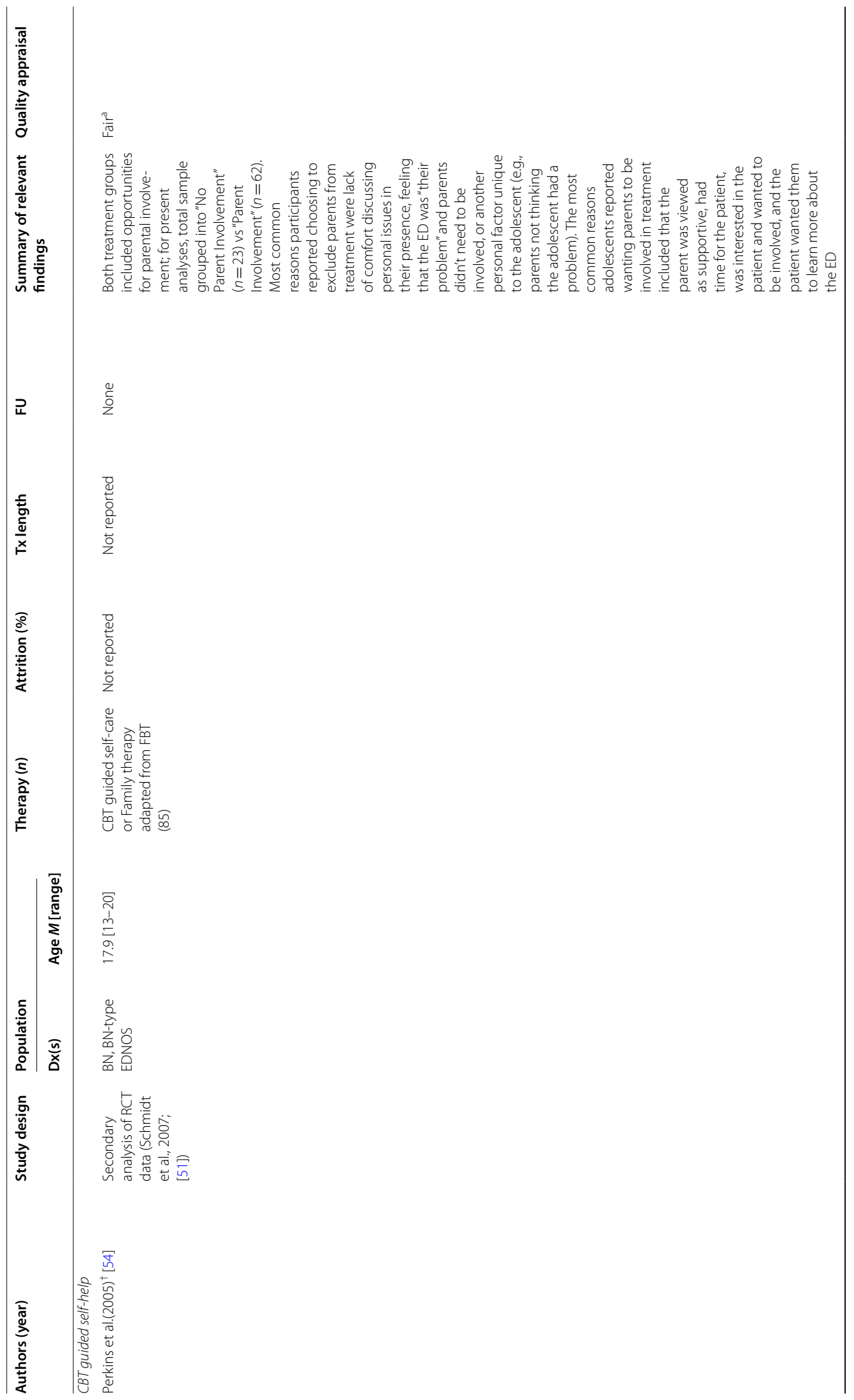




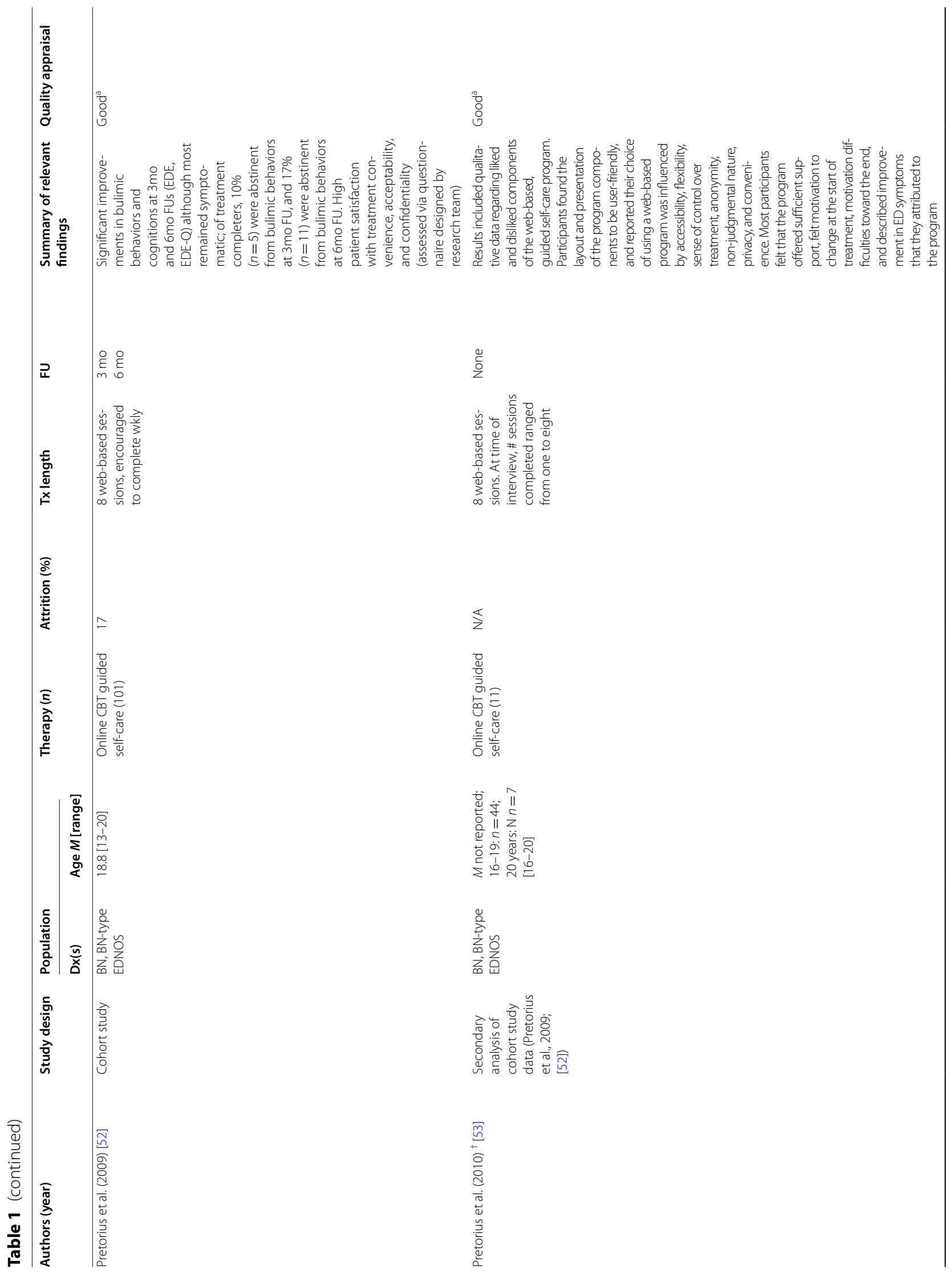




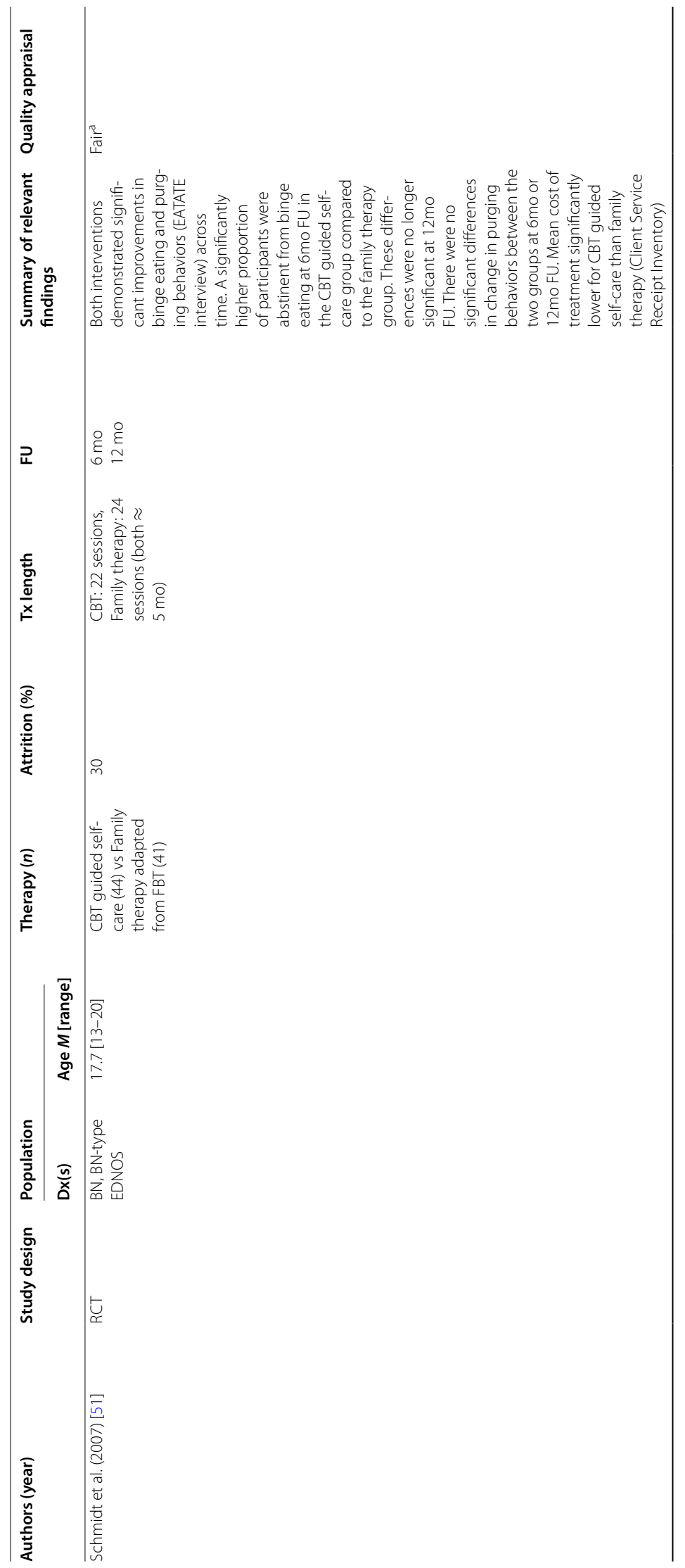




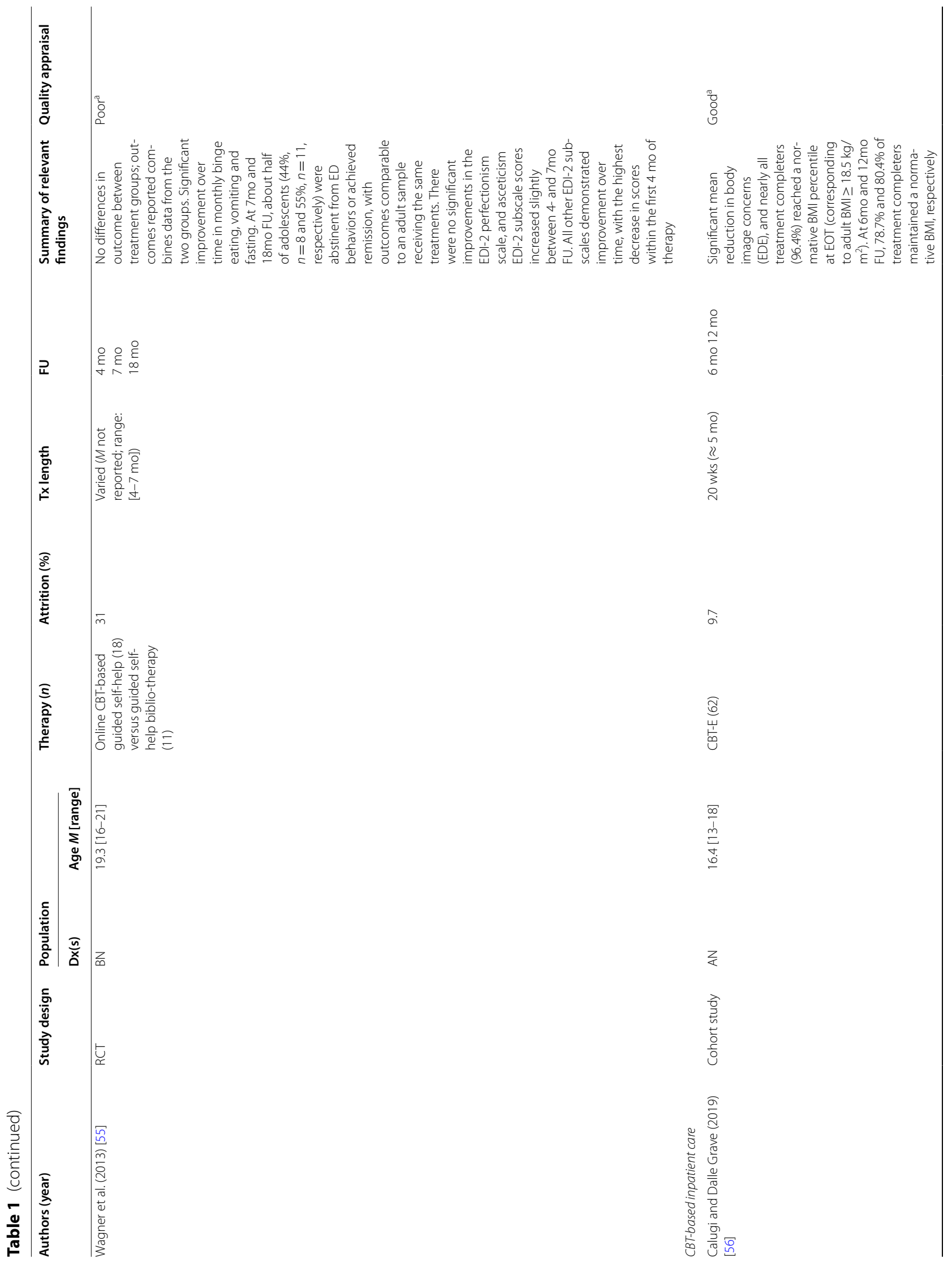




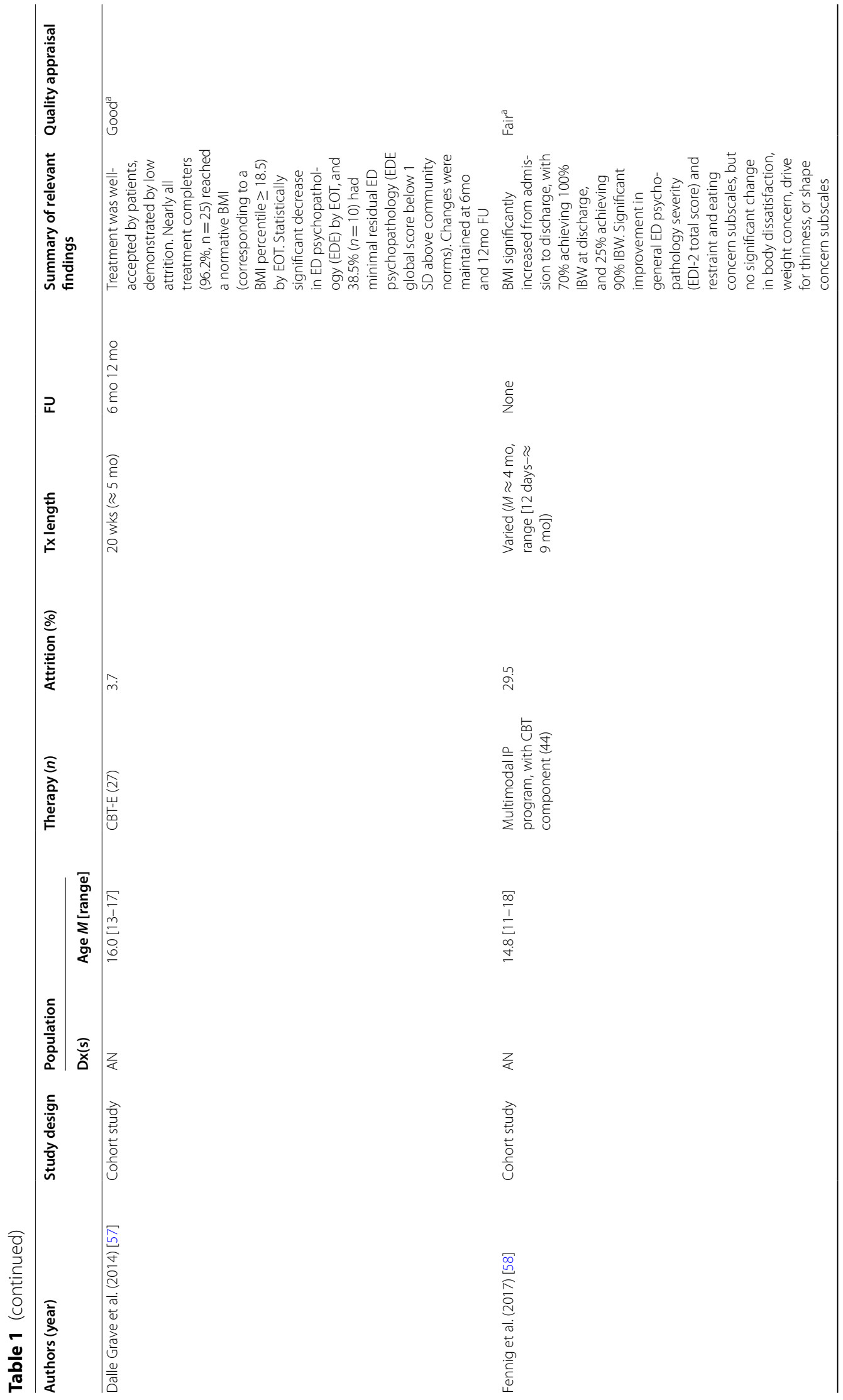




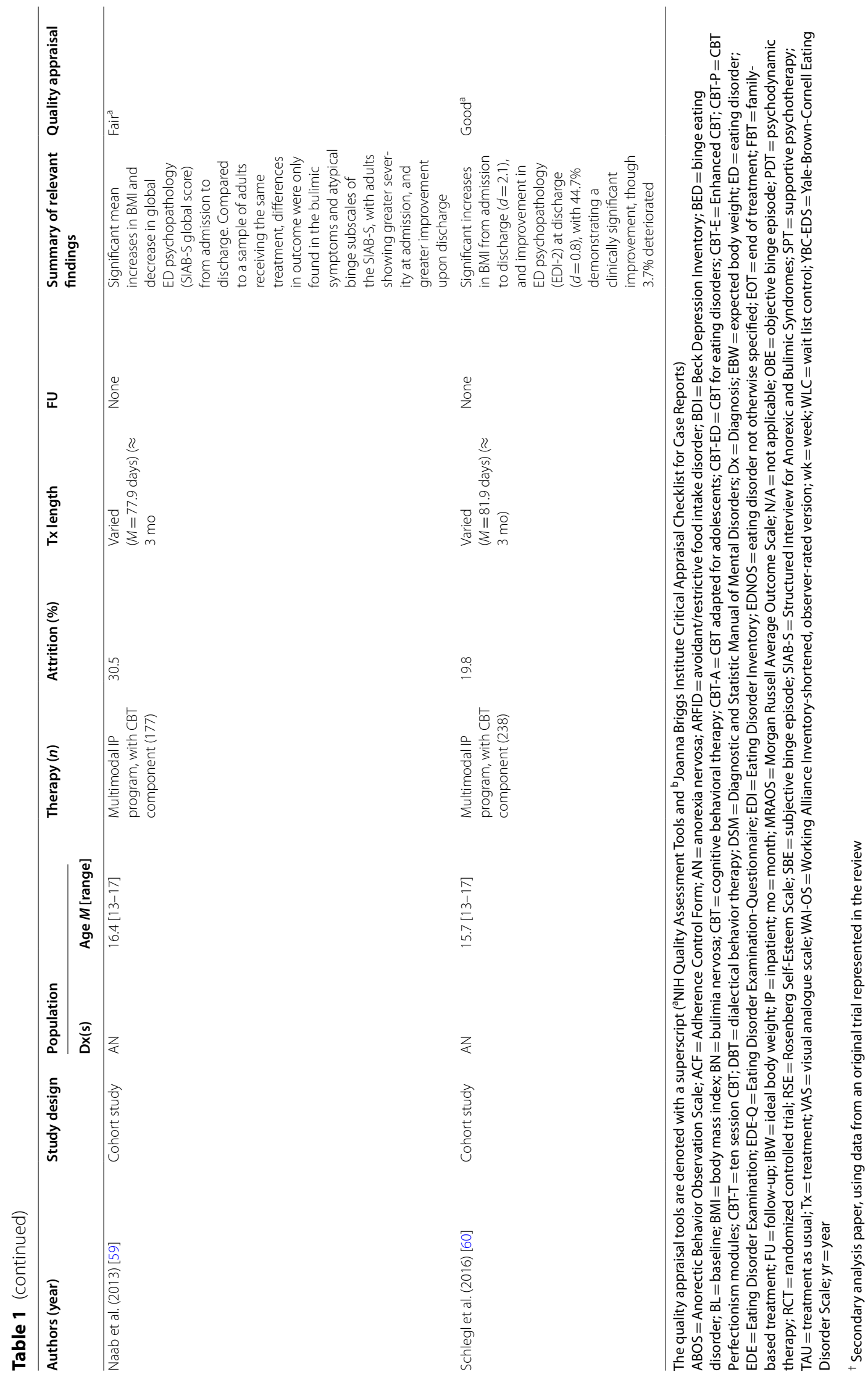




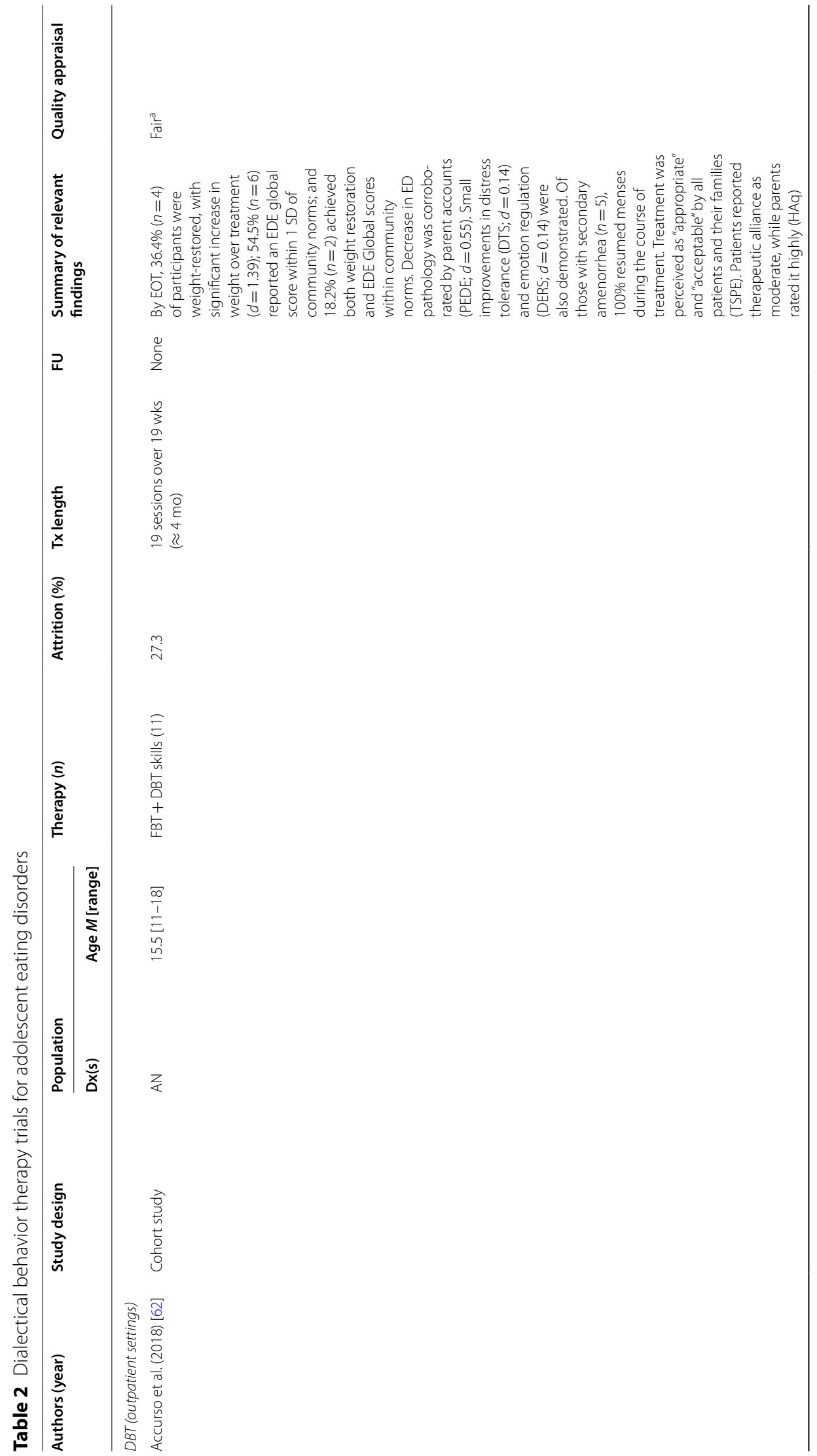




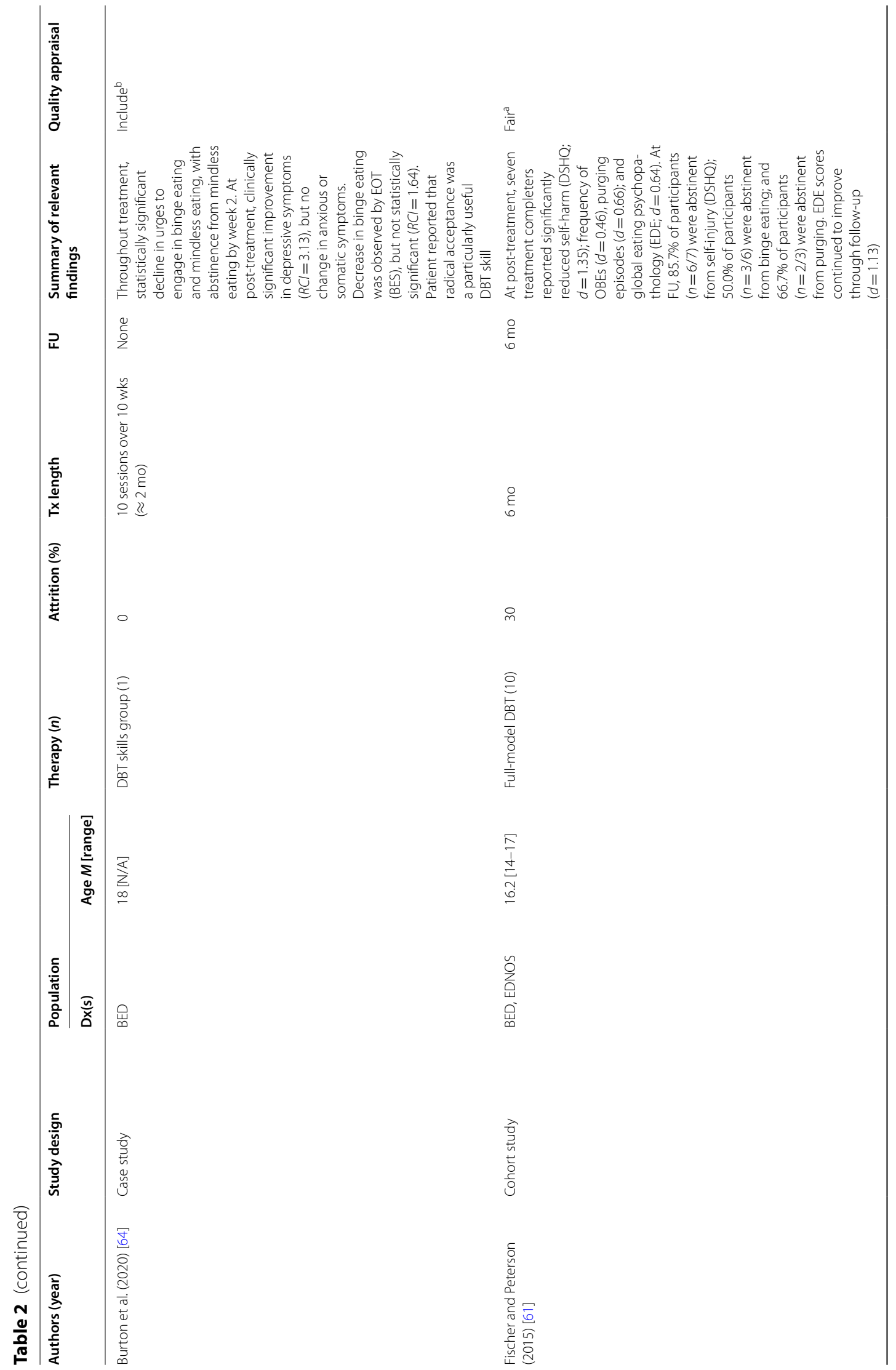




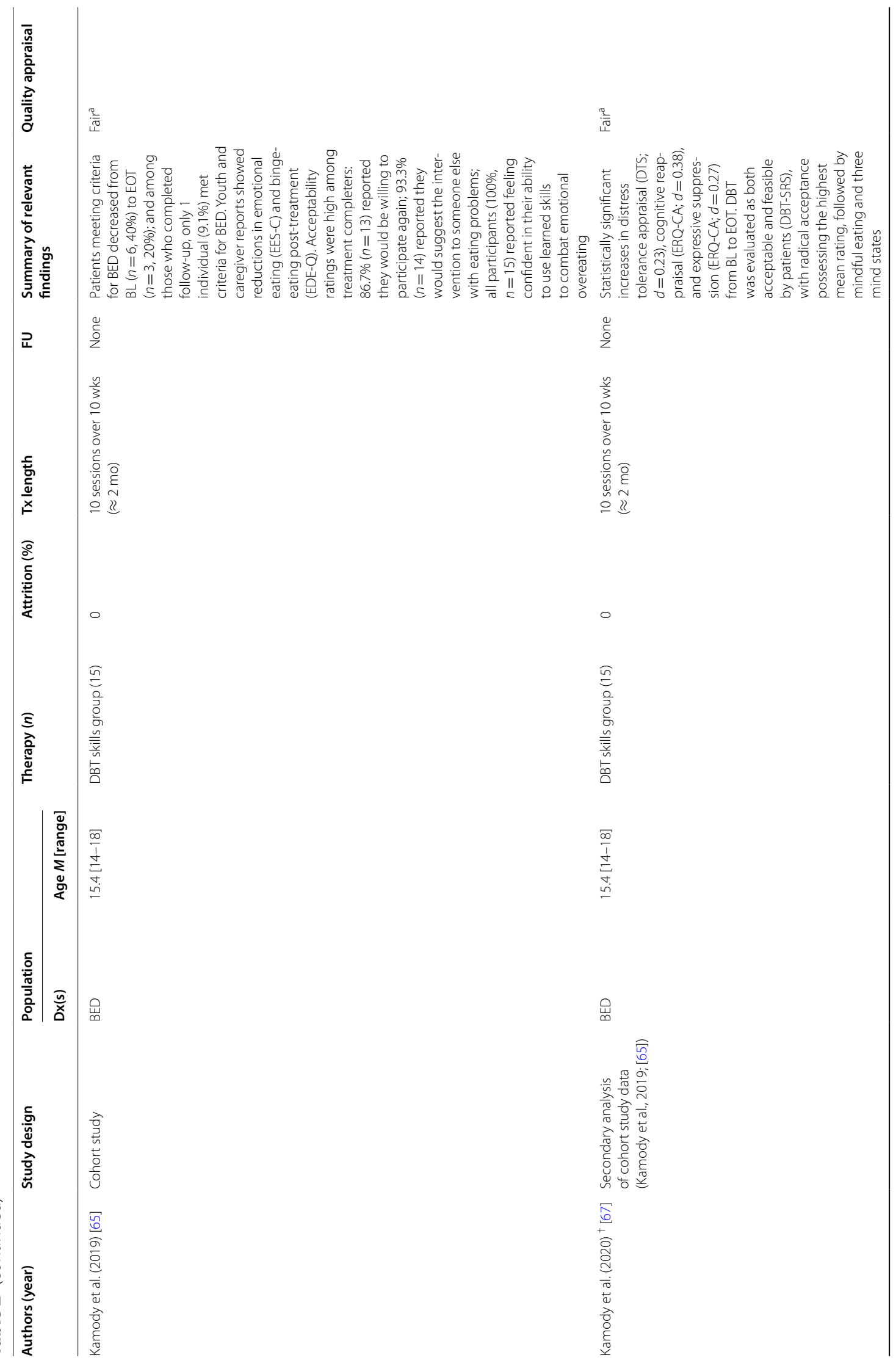




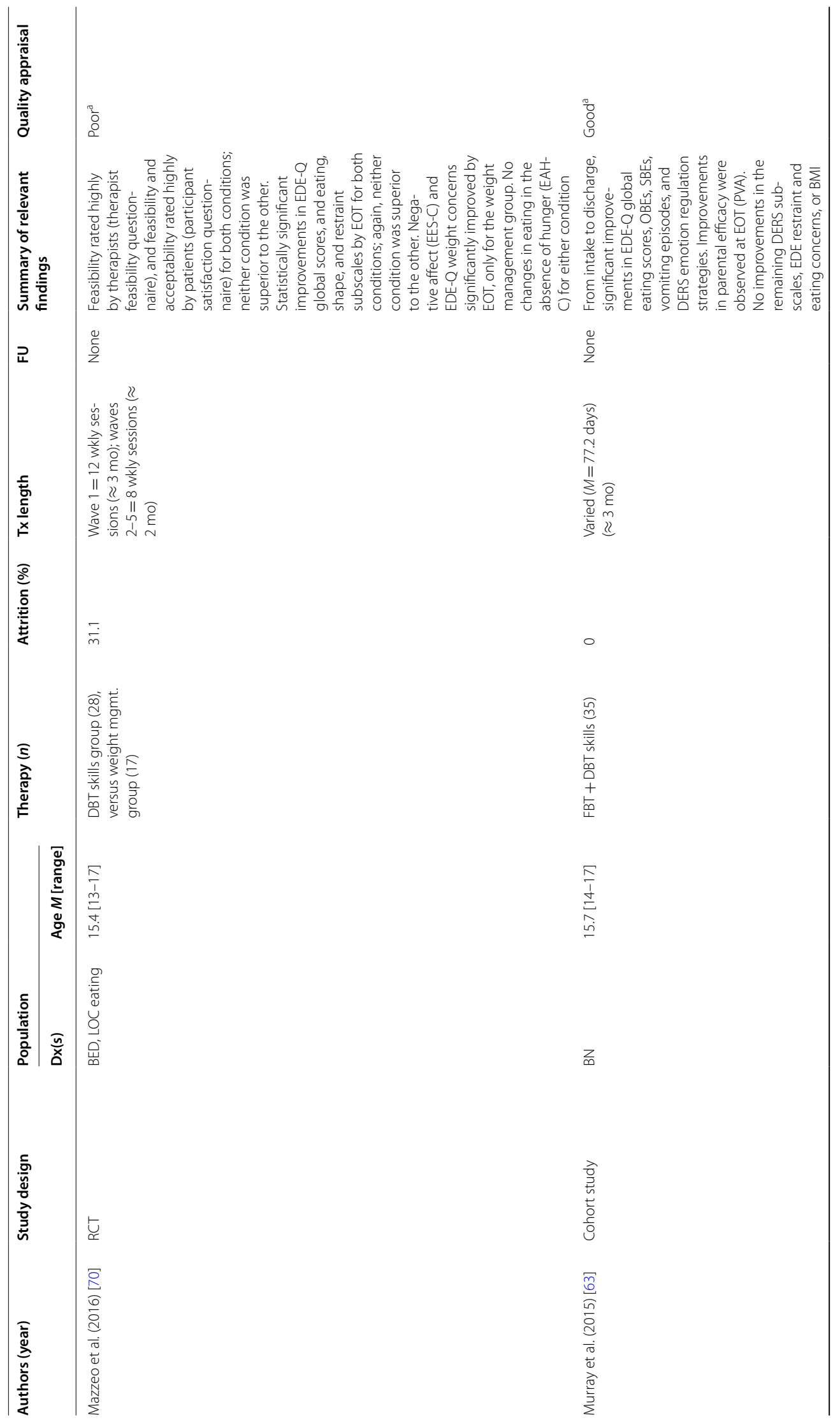




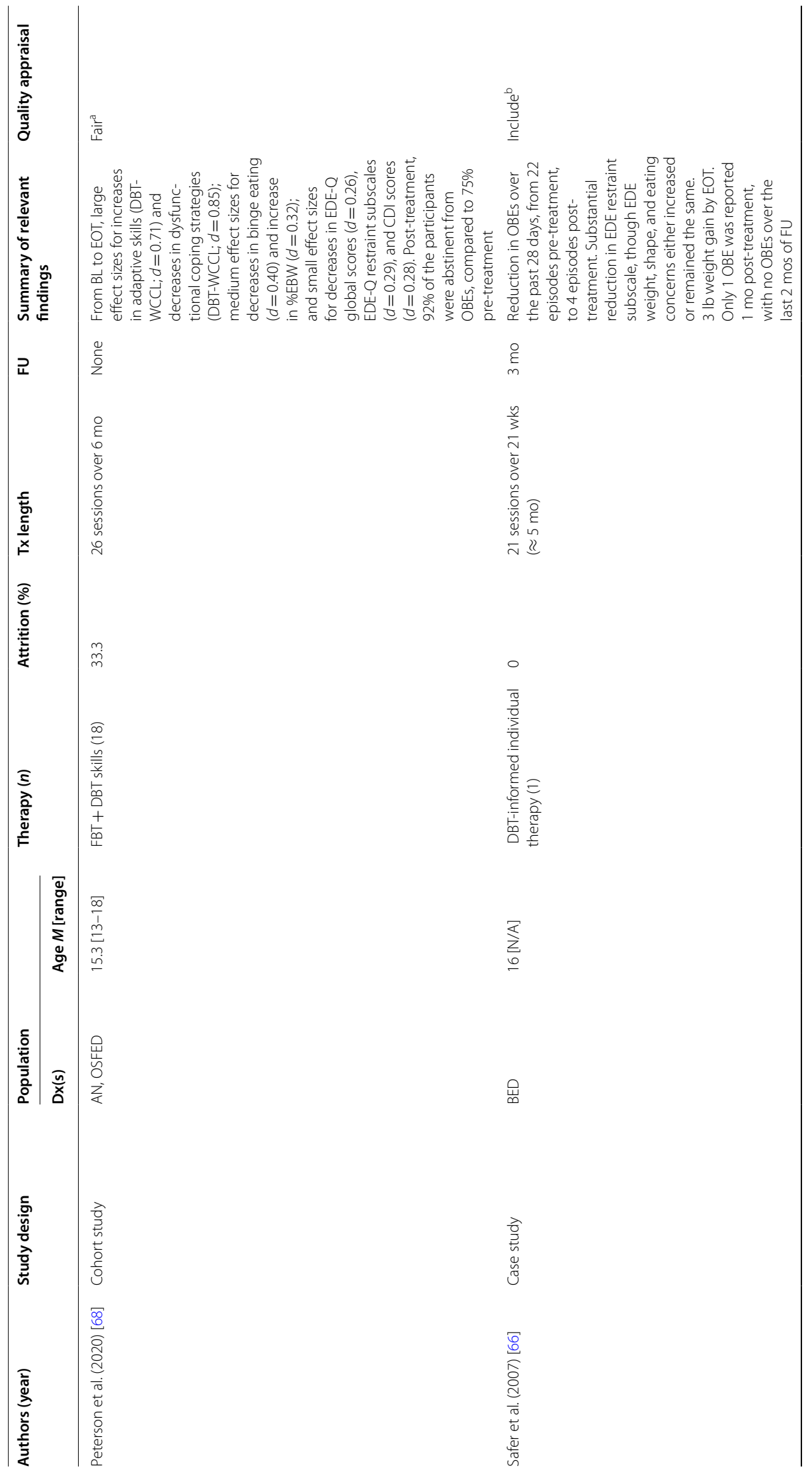




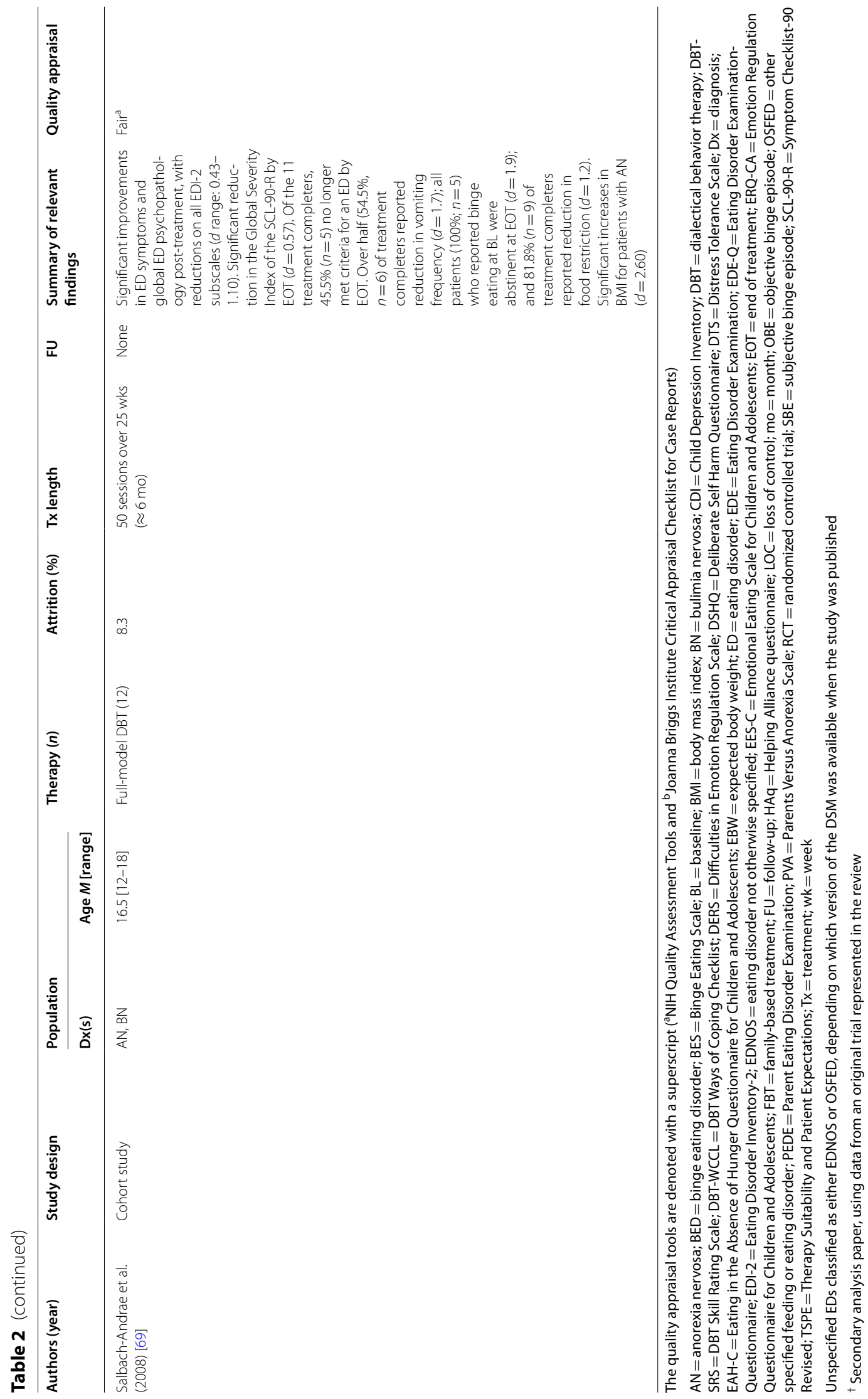




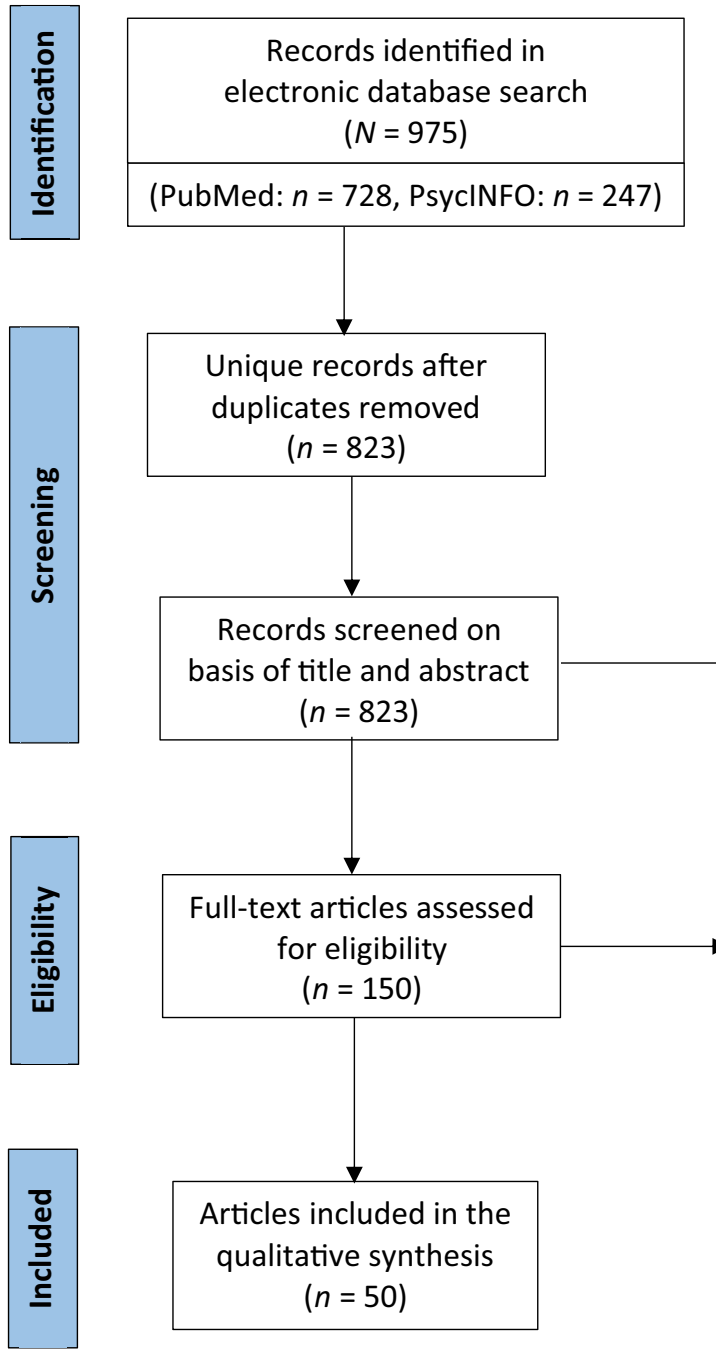

Records excluded $(n=673)$

Full-text articles excluded

$$
(n=100)
$$

Reasons for exclusion:

- Included adults in sample

- Did not include original research (i.e., review or therapy description)

- Not an eating disorders sample

- Did not include data related to the efficacy, effectiveness, feasibility or acceptability of CBT or DBT (e.g., case study that mentioned participation in, but did not discuss outcome of CBT/DBT component)

- Intervention conducted in PHP setting (excluded because too few studies that examined this intervention type)

- Not published in English

- Not published in a peer reviewed, academic journal (e.g., dissertation)

- Study quality appraisal rating of "exclude"

Fig. 1 PRISMA flow diagram [25]

predefined junctures in treatment (e.g., [31]). The majority of studies examined eating disorder psychopathology $(n=22)$ and/or behaviors $(n=15)$; less than half $(n=12)$ examined weight restoration.

\section{AN outcomes}

Results of randomized controlled trials and cohort studies $(n=10)$ supported the feasibility and acceptability of outpatient CBT for adolescent AN. Three studies 
evaluated manualized CBT-E, while other studies evaluated generic forms of CBT adapted for adolescent AN, group CBT, or a CBT module integrated with FBT. Mean treatment attrition was 24\% (range: [9-31], $n=9$ ), and studies demonstrated higher parent satisfaction with CBT than community-based usual care, [32] but no significant difference in satisfaction between CBT and DBT [33], and no difference in cost between CBT, communitybased care, or hospitalization [34]. Effectiveness was partially supported. Statistically significant improvements in weight and/or body mass index was observed $(n=4)$, though the proportion of participants that reached normative weight (i.e., 95\% expected body weight) by the end of treatment varied from one third [35] to about one half $[31,36]$. While eating disorder psychopathology also significantly improved in the majority of studies that reported this outcome $(n=5 / 7,71.4 \%)$, clinical significance was mixed. Normative levels of eating disorder psychopathology were achieved by the end of treatment for nearly all patients in one study [35], while all patients in another study remained symptomatic at the end of treatment [37]. Multiple studies $(n=4)$ did not report on clinical significance (i.e., effect sizes or interpretation of eating disorder psychopathology scores).

Finally, only two studies used a definition of remission that set a high bar for both cognitive (i.e., global eating disorder psychopathology within community norms) and weight status (i.e., achieved $95 \%$ expected body weight, or body mass index equivalent to an adult body mass index $\geq 18.5 \mathrm{~kg} / \mathrm{m}^{2}$ ) outcome. These studies suggested that over half of adolescents who completed treatment achieved full remission post-treatment, in CBT-E [31] and an intervention that integrated a CBT module within FBT [36]. Randomized controlled trial data $(n=3)$ found that CBT was neither superior nor inferior to other active treatments (i.e., behavioral family therapy, DBT, inpatient, or community-based care) with respect to eating disorder psychopathology or weight outcomes.

\section{BN outcomes}

Of the cohort studies and randomized controlled trials that investigated CBT for adolescent $\mathrm{BN}(n=6)$, most $(n=5)$ used a manualized version of CBT adapted for adolescents from the Fairburn [38] manual for adult BN, while one study [39] used a manualized version of CBT derived from CBT-E [10], but adapted to the treatment setting [40]. Across studies, acceptability was supported by relatively low attrition $(M=14 \%$, range: [0-39]), and effectiveness was supported by clinically meaningful and statistically significant improvement in eating disorder psychopathology. By the end of treatment, two studies reported significant reductions in binge eating and purging $[39,41]$, while one reported reductions in binge eating only [42]. Both cohort studies found that over half the sample was abstinent from binge eating and purging at the end of treatment $[42,43]$. Further, the two studies that reported improvements in eating disorder psychopathology and behaviors (both binge eating and purging) at the end of treatment found that gains were maintained at 3 - and 12-month follow-ups [39, 41].

Randomized controlled trial results demonstrated that FBT-compared to CBT-resulted in superior reductions in binge eating and purging at the end of treatment and 6-month follow-up, though outcomes were no longer different between treatment groups at 12-month follow-up [44]. Improvements in cognitive components of eating disorder psychopathology [44], depression, and self-esteem did not differ between CBT and FBT at any time-point [45]. In another study, patients who received CBT showed slightly greater reductions in frequency of binge eating and purging but somewhat less improvement in eating concern at the end of treatment than those who received psychodynamic therapy, while psychodynamic therapy showed a small advantage over CBT in eating concern at the end of treatment [39]. Together, these findings indicate relatively small differences between outcomes with CBT and other active treatments.

\section{BED outcomes}

One study representing two articles investigated CBT for $\mathrm{BED}$, using a manual for adult BED adapted for adolescents. Attrition rate was 32\%, though results showed high levels of therapist treatment adherence and therapeutic alliance [46], supporting feasibility and acceptability. Comparison to a wait-list control group demonstrated that the CBT group had significantly higher rates of abstinence from binge eating, significantly less eating disorder psychopathology, and greater diagnostic remission at the end of treatment [47]. In addition, the CBT group maintained its advantage relative to wait-list control in eating disorder behaviors and psychopathology at all follow-ups through two years.

\section{Transdiagnostic outcomes}

Two studies combined results for BN and BED; one reported on a transdiagnostic sample of adolescents with $\mathrm{AN}, \mathrm{BN}$, or eating disorder not otherwise specified; one reported results for any DSM- 5 eating disorder, excluding avoidant restrictive intake disorder. Studies evaluated manualized CBT-E $(n=2)$, CBT adapted (by the research team) for adolescents $(n=1)$, and eclectic approaches that integrated CBT components $(n=1)$. Feasibility and acceptability of the interventions was supported by an acceptable average attrition across three studies $(M=28.3 \%$, range: [23-37]) [30, 48, 49] and high 
post-treatment patient satisfaction in one study [30]. Effectiveness and efficacy were supported by statistically significant improvements in eating disorder psychopathology from pre- to post-treatment with a large effect size in a study evaluating CBT-E [48], and higher rates of abstinence from binge eating at the end of treatment compared to treatment as usual in a study evaluating an adaptation of CBT for adolescents [30]. Further, an effectiveness trial demonstrated that though rate of weight gain was slower in CBT-E compared to FBT at the end of treatment, there were no differences in weight gain between the treatments six months and one year later, and no differences in eating disorder psychopathology or most measures of global psychopathology and clinical impairment at any time point [49]. However, treatment was not assigned but rather chosen by patients and their families, such that baseline differences between treatment groups (e.g., age, duration of illness) were not unexpected. Finally, an observational cross-sectional study found that participants with poor relational/personality functioning did particularly well in eclectic forms of CBT [50].

\section{Guided self-help for BN}

Five articles representing three different studies (two randomized controlled trials, one cohort study) assessed the feasibility, acceptability, effectiveness and/or efficacy of CBT guided self-help for adolescents, all of which focused exclusively on BN. The interventions were delivered online $(n=1)$, via bibliotherapy $(n=1)$, or compared online and bibliotherapy formats $(n=1)$. Minimal, optional parent involvement was reported in two studies [51, 52]. Variables studied included eating disorder psychopathology, treatment satisfaction, and treatment cost. All three studies included follow-up data. Average attrition across studies was $26 \%$ (range: [17-31], $n=3$ ). Acceptability was further supported by high adolescent satisfaction with treatment [52], a preference for a selfhelp format in adolescents wishing to exclude parents from care, and/or seeking increased flexibility and anonymity [53]. Qualitative interview data indicated that guided self-help may be a feasible and acceptable "stepping stone" toward seeking in-person therapy [53]. Feasibility was further supported by lower mean cost of treatment compared to an adapted form of FBT [54].

Statistically significant improvements were reported across all studies in bulimic behaviors (i.e., binge eating, purging and/or fasting; $n=3$ ), although rates of remission were modest. One study reported that about half of adolescents had achieved abstinence from behaviors or remission at the end of treatment [55], while another reported that the majority of adolescents remained symptomatic at the end of treatment and follow-up [52]. Two studies made comparisons to another treatment or treatment format. No differences emerged between online versus bibliotherapy guided self-help [55], and compared to family therapy, a significantly higher proportion of participants were abstinent from binge eating at 6-month follow-up in CBT guided self-help, though significant differences between these groups disappeared at 12-month follow-up [51].

\section{Inpatient treatment for AN}

Five cohort studies assessed acceptability and effectiveness for CBT-based inpatient care, all of which focused exclusively on AN. Three of the studies implemented a CBT component (individual and/or group CBT) within a program with multiple treatment components, while two examined inpatient programs based on CBT-E. The majority $(n=5)$ incorporated formal family sessions. All studies used weight restoration as a measure of outcome, and most $(n=5)$ examined eating disorder psychopathology. Only two studies reported follow-up data. Acceptability was supported by relatively low attrition $(M=19 \%$, range: [4-31], $n=5$ ). The effectiveness of inpatient programs based on CBT-E was excellent, with nearly all patients (96\%) across two studies achieving a normative body mass index at the end of treatment $[56,57]$. Results of studies that examined a multimodal treatment program with a CBT component were less strong. Patients across studies achieved statistically significant increases in body mass index, but results were mixed for the proportion who achieved a normative body mass index by discharge. One study found that the majority of patients achieved a normative body weight by the end of treatment [58], while body weight had not reached normative levels, on average, by discharge in two others $[59,60]$. Finally, there were statistically significant albeit clinically modest reductions in global eating disorder psychopathology across studies; in two studies, over half of participants continued to have clinically significant eating disorder psychopathology at discharge $[57,60]$.

\section{DBT for adolescent eating disorders Outpatient settings}

Ten articles representing nine different studies (i.e., one study produced one secondary analysis paper) investigated outpatient DBT for adolescent eating disorders. Across unique studies, DBT was implemented for adolescents with $\mathrm{AN}(n=1), \mathrm{BN}(n=1), \operatorname{BED}(n=3)$, and transdiagnostic eating disorders $(n=4)$. Most studies $(n=8,88.9 \%)$ were either cohort studies or case reports, and one was a randomized controlled trial. Interventions implemented full-model DBT (i.e., individual therapy, skills group, and phone coaching; $n=2$ ); DBT-informed individual therapy $(n=1)$; DBT skills groups $(n=3)$; and 
"DBT-informed" FBT ( $n=3)$; one study also incorporated an optional parent group [61]. All studies assessed eating disorder psychopathology, two assessed parent reports of eating pathology, and three examined DBT mechanisms of action (e.g., distress tolerance, emotion regulation, DBT skills use). Articles also examined aspects of feasibility and acceptability $(n=5)$, including patient satisfaction, treatment expectations, and therapeutic alliance. Fewer than half of studies $(n=2,20 \%)$ reported follow-up data.

\section{AN outcomes}

Only one outpatient study examined DBT-enhanced FBT in adolescents with AN [62]. Treatment was perceived as "appropriate" and "acceptable" by all patients and their parents with moderate to high ratings of therapeutic alliance, respectively. Acceptability was further supported by a moderate attrition rate (27\%). Patients demonstrated significant increases in weight across treatment, with a little over one third achieving weight restoration and over half demonstrating clinically meaningful changes in eating disorder psychopathology at the end of treatment. Small improvements in distress tolerance and emotion regulation also suggested that the intervention was effective in promoting symptom reduction in targeted domains.

\section{BN outcomes}

One study examined DBT-enhanced FBT in adolescents with BN [63]. Acceptability was highly supported by $100 \%$ treatment retention. By the end of treatment, patients reported significant improvements in global eating disorder psychopathology, binge eating, and vomiting, and improvements in parental efficacy and patient emotion regulation were observed.

\section{BED outcomes}

Four articles representing three different studies examined individual and group DBT for adolescents with BED. Acceptability was supported by $100 \%$ treatment retention in all studies. Studies demonstrated high patient satisfaction, with DBT skills groups being rated as feasible, acceptable, and helpful $[64,65]$. Patients reported significant decreases in binge eating by the end of treatment in all studies, and $80 \%$ of patients no longer met criteria for BED post-treatment in one [65]. Significant decreases in emotional eating [65] and mindless eating [64] were also observed. Notably, Safer et al. [66] found significant reductions in eating restraint, but not weight, shape, or eating concerns, post-treatment. In another study [64], depression scores improved throughout treatment, but anxious and somatic symptoms remained unchanged. Only one study, a case report of DBT-informed individual therapy [66], presented follow-up data and found further reduction in binge episodes by 3-month follow-up.

In studies that examined DBT skills group mechanisms, patients with BED consistently rated radical acceptance as the most helpful skill $[64,67]$, followed by mindful eating, and three mind states [67]. By the end of treatment, patients showed increases in distress tolerance, cognitive reappraisal, and expressive suppression.

\section{Transdiagnostic outcomes}

Studies that investigated the feasibility and acceptability of DBT and DBT-informed therapies for transdiagnostic eating disorder samples (i.e., AN, BN, BED, and/or eating disorder not otherwise specified) found that both therapists and patients rated the treatment highly. Across all four studies, acceptability was further supported by relatively low attrition $(M=26 \%$, range: [8-33]), and treatment effectiveness was supported by significant improvements in global eating disorder psychopathology. Patients with binge eating and/or purging at baseline either reported significant reductions in $[61,68]$ or abstinence from these behaviors by the end of treatment [69]. Depressive symptomatology also showed marked improvement post-treatment [69]. Patients demonstrated continued improvement through follow-up, with the majority of patients across studies reporting abstinence from non-suicidal self-injury, binge eating, and purging; and further decreases in global eating disorder psychopathology [61]. One study found large effect sizes for increases in adaptive skills and decreases in dysfunctional coping strategies [68], suggesting high therapist fidelity to the treatment model that effectively targeted the intended mechanisms of change.

Mazzeo et al. [70] performed the only randomized controlled trial, comparing a DBT skills group to a weight management control group for BED and loss-of-control eating. DBT was feasible and satisfactory (although somewhat less so than for weight management), and patients demonstrated similar improvements in global eating disorder psychopathology as those who received weight management. However, the DBT group did not demonstrate improvement in weight concerns, while the weight management group did.

\section{Discussion}

Treatment outcomes for adolescent eating disorders remain modest, highlighting the need for innovative and novel treatment approaches. This review concludes that CBT and DBT-informed interventions have good feasibility and acceptability for adolescent eating disorders, with rates of attrition comparable to FBT trials [8, 71]. Studies also demonstrated high rates of treatment satisfaction, therapeutic alliance, and treatment fidelity, but 
data establishing effectiveness and efficacy compared to other leading approaches were mixed or incomplete.

The effectiveness of CBT for AN received partial support with mixed results across studies, though efficacy trials demonstrated that CBT for AN was neither inferior or superior to other outpatient (i.e., behavioral family therapy, DBT, community-based care) and inpatient treatments. Support for the effectiveness of CBT was strongest for $\mathrm{BN}$, with consistent, meaningful reductions in binge eating and purging across studies, while efficacy was supported by small differences in outcome compared to other active treatments (i.e., FBT or psychodynamic therapy). CBT guided self-help for BN also led to significant reductions in binge eating and purging and may have enhanced feasibility and acceptability for adolescents who might not otherwise engage in treatment. Meanwhile, weight restoration outcomes were stronger in inpatient programs based on CBT-E for AN relative to eclectic inpatient programs, though replication by alternative research teams would help clarify their feasibility. However, there was a paucity of CBT studies for diagnoses other than $\mathrm{AN}$ or $\mathrm{BN}$, and additional effectiveness and efficacy trials are needed across eating disorder diagnoses.

A lack of trials comparing CBT to FBT for AN emerged as a particularly notable gap in the literature, given that FBT is widely considered the first line treatment for adolescent AN but is not always feasible (due to factors such as family capacity/preferences, as well as clinician preferences). Comparisons of FBT to CBT have supported the effectiveness of CBT-E for a majority underweight transdiagnostic eating disorders sample [49], as well as the efficacy of CBT for BN [44]; FBT resulted in faster improvement, but CBT "caught up" with no differences in outcome one-year post-treatment in both studies. Hybrid designs that randomize patients to treatment in real world settings are needed to compare FBT to CBT for AN to clarify their relative efficacy and moderators of treatment outcome. Consistent definitions of remission and attention to the clinical significance of outcomes, particularly in studies of $\mathrm{AN}$, were also lacking and would improve the interpretation of the relative effectiveness and efficacy of CBT versus FBT in future studies.

DBT and DBT-informed treatments demonstrated high levels of feasibility, acceptability, and effectiveness, with reductions in global eating pathology and behaviors across eating disorders. Support for the effectiveness of DBT and DBT-informed interventions was strongest for $\mathrm{BN}$ and BED with consistent reductions in or abstinence from binge eating by the end of treatment, and significant reductions in purging for those with $\mathrm{BN}$. The only available randomized controlled trial comparing DBT to weight management found no significant differences in outcomes for BED and loss-of-control eating. Additional randomized controlled trials are thus needed to understand the efficacy of DBT, particularly compared to other treatments over the long-term, given potential differences between treatments that may not emerge in the absence of follow-up data.

Several differences between CBT and DBT emerged. First, contrary to CBT, there were no studies evaluating DBT adapted in inpatient settings. The ability for CBT (particularly CBT-E; $[56,57]$ ) to span inpatient and outpatient settings enables a stepped care approach that may facilitate continuity when transitioning between levels of care (e.g., prevent confusion for adolescents and caregivers due to disparate strategies at different levels of care). While such continuity may be possible in the context of DBT-informed higher level of care programs, these have not yet been studied. Second, though "pure" CBT (i.e., manualized CBT or CBT-E) was evaluated for the treatment of $\mathrm{AN}$ and $\mathrm{BN}$, "pure" DBT was evaluated primarily for BED, with DBT skills being integrated within FBT for $\mathrm{AN}$ and $\mathrm{BN}$. Indeed, CBT may better target mechanisms hypothesized to maintain AN and BN (e.g., overvaluation of shape and weight), while DBT may be better suited to target mechanisms that maintain psychopathology in BED (e.g., emotion dysregulation). As such, CBT may be more appropriate to compare to FBT than DBT for the treatment of $\mathrm{AN}$ and $\mathrm{BN}$, particularly in randomized controlled trials examining mediators of change, as it would not be possible to identify mediators when comparing treatments with overlapping components (e.g., FBT vs DBT integrated with FBT).

Notably, though this systematic review aimed to be comprehensive with the inclusion of non-randomized designs and thoughtful selection of key search terms, it is possible that the keyword search did not encompass all relevant articles, and studies published after December 2020 were not included. The risk of bias assessment revealed multiple limitations across studies: small sample sizes, biased samples limiting generalizability, inconsistent reporting of follow-up data, and inconsistent reporting of elements critical to study quality assessment, including power to detect an effect, and effect sizes. In addition, many studies failed to report race/ethnicity, and the majority of those that did recruited all or majority non-Hispanic White samples. Most studies also recruited majority female or female-only samples. The homogeneity of these samples is an underrepresentation of the diversity in sex, gender identity, race, and ethnicity within the eating disorders population [72-74]. The implementation of treatments also varied considerably across studies, with multiple studies integrating elements of CBT or DBT within other treatments. While this limits conclusions about the specific, unique impact of CBT 
or DBT, combination treatments may hold promise in enhancing treatment outcome. For instance, FBT combined with cognitive-behavioral techniques may capitalize on the benefit of family supervision and support while also addressing maladaptive cognitions [36]. However, randomized designs are needed to clarify whether CBT may have advantages for certain patients (e.g., through identification of treatment moderators), and whether hybrid forms of treatment (e.g., integrating CBT or DBT with FBT) may enhance patient outcomes.

\section{Conclusions}

CBT and DBT demonstrated good feasibility, acceptability, and preliminary effectiveness across adolescent eating disorders in real-world clinical settings, but their efficacy relative to more established treatments is largely unexamined. Ultimately, the availability of additional evidence-based treatments offers an alternative to FBT, which currently predominates in the treatment of adolescent eating disorders, and is insufficient for some families (e.g., due to family factors such as a history of caregiver abuse, lack of caregiver availability or other barriers to treatment engagement, including caregiver unwillingness possibly affected by poor cultural acceptability and stigma related to mental health and mental health treatment; or co-occurring disorders and/or other psychopathology better managed within a DBT framework).

New treatments or even existing treatments blended with new treatments may enhance outcomes for difficult-to-treat populations or reduce risk of relapse. We recommend that future research: (1) use adequately powered, randomized designs with representative transdiagnostic eating disorder samples under real-world conditions to compare CBT and DBT to other leading treatments (including FBT); (2) evaluate the relative utility of "pure" versus integrated/hybrid forms of treatment (e.g., the efficacy of broad CBT-E vs CBT integrated with FBT); (3) assess treatment moderators to better guide treatment matching; (4) evaluate mediators of treatment response, and reasons for non-response to inform treatment modifications that improve efficacy and efficiency; and (5) improve the consistency of reporting elements critical to study quality assessment-power and effect sizes-to improve the interpretation of outcomes. Advancing research on alternative treatment options is imperative given the serious consequences of eating disorders [4], relative likelihood for a severe and enduring presentation $[75,76]$, and remission rates for leading treatments.

\section{Abbreviations}

AN: Anorexia nervosa; BED: Binge eating disorder; BN: Bulimia nervosa; CBT: Cognitive behavior therapy; CBT-E: Enhanced cognitive behavior therapy; DBT: Dialectical behavior therapy; FBT: Family-based treatment; NIH: National Institute of Health.

\section{Acknowledgements \\ Not applicable.}

\section{Authors' contributions}

ECA conceptualized the review aims and outline. ENV and SS performed the systematic search, extraction of studies and variables, and completed the qualitative analysis and study quality appraisal. ECA provided consultation regarding review methodology, study inclusion, and study quality appraisal. ENV and SS drafted the manuscript, and ECA provided critical revision. All authors read and approved the final manuscript.

\section{Funding}

None.

\section{Availability of data and materials}

The datasets used during the current study are available from the corresponding author on reasonable request.

\section{Declarations}

Ethics approval and consent to participate

Not applicable.

\section{Consent for publication}

Not applicable.

\section{Competing interests}

The authors declare that they have no competing interests.

\section{Author details}

${ }^{1}$ PGSP-Stanford PsyD Consortium, Palo Alto University, Palo Alto, CA, USA. ${ }^{2}$ Department of Psychological and Brain Sciences, Drexel University, Philadelphia, PA, USA. ${ }^{3}$ Department of Psychiatry and Behavioral Sciences, UCSF Weill Institute for Neurosciences, University of California, San Francisco, CA, USA.

Received: 27 April 2021 Accepted: 10 August 2021

Published online: 18 October 2021

\section{References}

1. Hudson JI, Hiripi E, Pope HG, Kessler RC. The prevalence and correlates of eating disorders in the National Comorbidity Survey Replication. Biol Psychiatry. 2007;61(3):348-58. https://doi.org/10.1016/j.biopsych.2006.03. 040.

2. Yao S, Kuja-Halkola R, Martin J, Lu Y, Lichtenstein P, et al. Associations between attention-deficit/hyperactivity disorder and various eating disorders: a Swedish nationwide population study using multiple genetically informative approaches. Biol Psychiatry. 2019;86(8):577-86. https:// doi.org/10.1016/j.biopsych.2019.04.036.

3. Iwajomo T, Bondy SJ, de Oliveira C, Colton P, Trottier K, Kurdyak P. Excess mortality associated with eating disorders: population-based cohort study. Br J Psychiatry. 2020. https://doi.org/10.1192/bjp.2020.1.

4. van Hoeken D, Hoek HW. Review of the burden of eating disorders: mortality, disability, costs, quality of life, and family burden. Curr Opin Psychiatry. 2020;33(6):521. https://doi.org/10.1097/YCO.000000.

5. Chidiac CW. An update on the medical consequences of anorexia nervosa. Curr Opin Pediatr. 2019;31(4):448-53. https://doi.org/10.1097/MOP. 0000000000000755.

6. Lock J. An update on evidence-based psychosocial treatments for eating disorders in children and adolescents. J Clin Child Adolesc Psychol. 2015;44(5):707-21. https://doi.org/10.1080/15374416.2014.971458.

7. Le Grange D, Crosby RD, Rathouz PJ, Leventhal BL. A randomized controlled comparison of family-based treatment and supportive 
psychotherapy for adolescent bulimia nervosa. Arch Gen Psychiatry. 2007;64(9):1049-56. https://doi.org/10.1001/archpsyc.64.9.1049.

8. Lock J, Le Grange D, Agras WS, Moye A, Bryson SW, Jo B. Randomized clinical trial comparing family-based treatment with adolescent-focused individual therapy for adolescents with anorexia nervosa. Arch Gen Psychiatry. 2010;67(10):1025-32. https://doi.org/10.1001/archgenpsychiat ry.2010.128.

9. National Institute for Health and Care Excellence. Eating disorders: recognition and treatment (NG69). NICE; 2017.

10. Fairburn C. Cognitive behavior therapy and eating disorders. Guilford Press; 2008.

11. Dalle Grave R, Calugi S. Cognitive behavior therapy for adolescents with eating disorders. Guilford Press; 2020.

12. Fairburn CG, Cooper Z, Shafran R. Cognitive behaviour therapy for eating disorders: a transdiagnostic theory and treatment. Behav Res Ther. 2003;41:509-28. https://doi.org/10.1016/s0005-7967(02)00088-8.

13. Strawn JR, Lu L, Peris TS, Levine A, Walkup JT. Research review: pediatric anxiety disorders - what have we learnt in the last 10 years? J Child Psychol Psychiatry. 2021;62(2):114-39. https://doi.org/10.1111/jcpp.13262.

14. Viswanathan M, Kennedy SM, McKeeman J, Christian R, Coker-Schwimmer M, Middleton JC, et al. Treatment of depression in children and adolescents: a systematic review. J Comp Eff Res. 2020. https://doi.org/10. 23970/AHRQEPCCER224.

15. Wilson GT, Sysko R. Cognitive-behavioural therapy for adolescents with bulimia nervosa. Eur Eat Disord Rev. 2006;14(1):8-16. https://doi.org/10. 1002/erv.668.

16. Linehan MM. Skills training manual for treating borderline personality disorder. Guildford Press; 1993.

17. Miller AL, Rathus JH, Linehan MM, Wetzler S, Leigh E. Dialectical behavior therapy adapted for suicidal adolescents. J Psychiatr Pract. 1997;3(2):78. https://doi.org/10.1177/0884533609357566.

18. Klein DA, Miller AL. Dialectical behavior therapy for suicidal adolescents with borderline personality disorder. Child Adolesc Psychiatr Clin N Am. 2011;20(2):205-16. https://doi.org/10.1016/j.chc.2011.01.001.

19. Lynch TR, Morse JQ, Mendelson T, Robins CJ. Dialectical behavior therapy for depressed older adults: a randomized pilot study. Am J Geriatr Psychiatry. 2003;11(1):33-45. https://doi.org/10.1097/00019442-20030 1000-00006.

20. Dimeff $L A$, Linehan MM. Dialectical behavior therapy for substance abusers. Addict Sci Clin Pract. 2008;4(2):39. https://doi.org/10.1151/ascp0 84239.

21. Wisniewski L, Kelly E. The application of dialectical behavior therapy to the treatment of eating disorders. Cogn Behav Pract. 2003;10(2):131-8. https://doi.org/10.1016/S1077-7229(03)80021-4.

22. Hamadi L, Holliday J. Moderators and mediators of outcome in treatments for anorexia nervosa and bulimia nervosa in adolescents: a systematic review of randomized controlled trials. Int J Eat Disord. 2019;53(3):319. https://doi.org/10.1002/eat.23159.

23. Weisz JR, Chu BC, Polo AJ. Treatment dissemination and evidence-based practice: strengthening intervention through clinician-researcher collaboration. Clin Psychol. 2004;11(3):300-7. https://doi.org/10.1093/clipsy. bph085.

24. Linardon J, Fairburn CG, Fitzsimmons-Craft EE, Wilfley DE, Brennan L. The empirical status of the third-wave behaviour therapies for the treatment of eating disorders: a systematic review. Clin Psychol Rev. 2017;58:125-40. https://doi.org/10.1016/j.cpr.2017.10.005.

25. Moher D, Liberati A, Tetzlaff J, Altman DG, PRISMA Group. Preferred reporting items for systematic reviews and meta analyses: the PRISMA statement. PLoS Med. 2009;6(7):e1000097. https://doi.org/10.1371/journ al.pmed1000097.

26. Ma LL, Wang YY, Yang ZH, Huang D, Weng H, Zeng XT. Methodological quality (risk of bias) assessment tools for primary and secondary medical studies: what are they and which is better? Military Med Res. 2020. https://doi.org/10.1186/s40779-020-00238-8.

27. National Institute of Health. Study Quality Assessment Tools. National Heart, Lung and Blood Institute; [updated 2021 July; cited 2021 July]. https://www.nhlbi.nih.gov/health-topics/study-quality-assessment-tools.

28. Moola S, Munn Z, Tufanaru C, Aromataris E, Sears K, Sfetcu R, Currie M, Lisy K, Qureshi R, Mattis P, Mu P. Chapter 7: systematic reviews of etiology and risk. In: Aromataris E, Munn Z, editors. JBI manual for evidence synthesis. Joanna Briggs Institute; 2020. https://doi.org/10.46658/JBIMES-20-08.
29. Mathes T, Pieper D. Clarifying the distinction between case series and cohort studies in systematic reviews of comparative studies: potential impact on body of evidence and workload. BMC Med Res Methodol. 2017;17:107.

30. Debar LL, Wilson GT, Yarborough BJ, Burns B, Oyler B, Hildebrandt T, et al. Cognitive behavioral treatment for recurrent binge eating in adolescent girls: a pilot trial. Cogn Behav Pract. 2013;20(2):147-61. https://doi.org/10. 1016/j.cbpra.2012.04.001.

31. Dalle Grave R, Sartirana S, Calugi S. Enhanced cognitive behavioral therapy for adolescents with anorexia nervosa: outcomes and predictors of change in a real-world setting. Int J Eat Disord. 2019;52:1042-6. https:// doi.org/10.1002/eat.23122.

32. Gowers SG, Clark AF, Roberts C, Byford S, Barrett B, Griffiths A, et al. A randomised controlled multicentre trial of treatments for adolescent anorexia nervosa including assessment of cost-effectiveness and patient acceptability - the TOuCAN trial. Health Technol Assess Rep. 2010;14(15):1-98. https://doi.org/10.3310/hta14150.

33. Jaite C, Pfeiffer A, Pfeiffer C, Thurn C, Bierbaum T, Winter SM, et al. Subjective evaluation of outpatient treatment for adolescent patients with anorexia nervosa. Eat Weight Disord. 2018;12(4):445-52. https://doi.org/ 10.1007/s40519-018-0620-0.

34. Byford S, Barrett B, Roberts C, Clark A, Edwards V, Smethurst N, et al. Economic evaluation of a randomised controlled trial for anorexia nervosa in adolescents. Br J Psychiatry. 2007;191:436-40. https://doi.org/10.1192/ bjp.bp.107.036806.

35. Dalle Grave R, Calugi S, Doll HA, Fairburn CG. Enhanced cognitive behavior therapy for adolescents with anorexia nervosa: an alternative to family therapy? Behav Res Ther. 2013;51(1):R9-12. https://doi.org/10.1016/j.brat. 2012.09.008

36. Hurst K, Zimmerbeck M. Family-based treatment with cognitive behavioural therapy for anorexia. Clin Psychol. 2019;23:61-70. https://doi.org/ 10.1111/cp.12152.

37. Ball J, Mitchell P. A randomized controlled study of cognitive behavior therapy and behavioral family therapy for anorexia nervosa patients. Eat Disord. 2004;12(4):303-14. https://doi.org/10.1080/10640260490521389.

38. Fairburn CG, Marcus MD, Wilson GT. Cognitive-behavioral therapy for binge eating and bulimia nervosa: a comprehensive treatment manual. In: Fairburn CG, Wilson GT, editors. Binge eating: nature, assessment, and treatment. Guilford Press; 1993. p. 361-404.

39. Stefini A, Salzer S, Reich G, Horn H, Winkelmann K, Bents H, et al. Cognitive-behavioral and psychodynamic therapy in female adolescents with bulimia nervosa: a randomized controlled trial. J Am Acad Child Sci. 2017;56(4):329-35. https://doi.org/10.1016/j.jaac.2017.01.019.

40. Bents H. Cognitive behavior therapy for bulimia nervosa in adolescentsa manual (trans. from German). Universitat Heidelberg; 2007.

41. Charpentier P, Marttunen M, Fadjukov S, Huttunen A. CBT for adolescent eating disorder patients: literature review and a report of an open trial of group CBT for adolescent outpatients with eating disorders. Psych Fenn. 2003;34:80-98.

42. Schapman-Williams AM, Lock J, Couturier J. Cognitive-behavioral therapy for adolescents with binge eating syndromes: a case series. Int J Eat Disord. 2006;39(3):252-5. https://doi.org/10.1002/eat.20253.

43. Lock J. Adjusting cognitive behavior therapy for adolescents with bulimia nervosa: results of a case series. Am J Psychother. 2005;59(3):267-81. https://doi.org/10.1176/appi.psychotherapy.2005.59.3.267.

44. Le Grange D, Lock J, Agras WS, Bryson SW, Jo B. Randomized clinical trial of family-based treatment and cognitive-behavioral therapy for adolescent bulimia nervosa. J Am Acad Child Psy. 2015;54(11):886-894.e2. https://doi.org/10.1016/j.jaac.2015.08.008.

45. Valenzuela F, Lock J, Le Grange D, Bohon C. Comorbid depressive symptoms and self-esteem improve after either cognitive-behavioural therapy or family-based treatment for adolescent bulimia nervosa. Eur Eat Disord Rev. 2018;26(3):253-8. https://doi.org/10.1002/erv.2582.

46. Puls HC, Schmidt R, Hilbert A. Therapist adherence and therapeutic alliance in individual cognitive-behavioural therapy for adolescent bingeeating disorder. Eur Eat Disord Rev. 2019;27(2):182-94. https://doi.org/10. 1002/erv.2650.

47. Hilbert A, Petroff D, Neuhaus P, Schmidt R. Cognitive-behavioral therapy for adolescents with an age-adapted diagnosis of binge-eating disorder: a randomized controlled trial. Psychother Psychosom. 2020;89:51-3. https://doi.org/10.1159/000503116. 
48. Dalle Grave R, Calugi S, Sartirana M, Fairburn CG. Transdiagnostic cognitive behaviour therapy for adolescents with an eating disorder who are not underweight. Behav Res Ther. 2015;73:79-82. https://doi.org/10. 1016/j.brat.2015.07.014.

49. Le Grange D, Eckhardt S, Dalle Grave R, Crosby RD, Peterson CD, Keery H, et al. Enhanced cognitive-behavior therapy and family-based treatment for adolescents with an eating disorder: a non-randomized effectiveness trial. Psychol Med. 2020. https://doi.org/10.1017/S0033291720004407.

50. Thompson-Brenner H, Boisseau CL, Satir DA. Adolescent eating disorders: treatment and response in a naturalistic study. J Clin Psychol. 2010;66(3):277-301. https://doi.org/10.1002/jclp.20646.

51. Schmidt U, Lee S, Beecham J, Perkins S, Treasure J, Yi I, et al. A randomized controlled trial of family therapy and cognitive behavior therapy guided self-care for adolescents with bulimia nervosa and related disorders. Am J Psychiatry. 2007;164(4):591-8. https://doi.org/10.1176/ajp.2007.164.4.591.

52. Pretorius N, Arcelus J, Beecham J, Dawson H, Doherty F, Eisler I, et al. Cognitive-behavioural therapy for adolescents with bulimic symptomatology: the acceptability and effectiveness of internet-based delivery. Behav Res Ther. 2009;47(9):729-36. https://doi.org/10.1016/j.brat.2009.05. 006.

53. Pretorius N, Rowlands L, Ringwood S, Schmidt U. Young people's perceptions of and reasons for accessing a web-based cognitive behavioural intervention for bulimia nervosa. Eur Eat Disord Rev. 2010;18(3):197-206. https://doi.org/10.1002/erv.985.

54. Perkins S, Schmidt U, Eisler I, Treasure J, Yi I, Winn S, et al. Why do adolescents with bulimia nervosa choose not to involve their parents in treatment? Eur Child Adolesc Psychiatry. 2005;14(7):376-85. https://doi. org/10.1007/s00787-005-0485-4.

55. Wagner G, Penelo E, Nobis G, Mayerhofer A, Schau J, Spitzer M, et al. Is technology assisted guided self-help successful in treating female adolescents with bulimia nervosa? Neuropsychiatrie. 2013;27(2):66-73. https://doi.org/10.1007/s40211-013-0062-x.

56. Calugi S, Dalle GR. Body image concern and treatment outcomes in adolescents with anorexia nervosa. Int J Eat Disord. 2019;52:582-5. https:// doi.org/10.1002/eat.23031.

57. Dalle Grave R, Calugi S, El Ghoch M, Conti M, Fairburn CG. Inpatient cognitive behavior therapy for adolescents with anorexia nervosa: Immediate and longer-term effects. Front Psychiatry. 2014;5:14. https://doi.org/10. 3389/fpsyt.2014.00014.

58. Fennig S, Klomek AB, Shahar B, Sarel-Michnik ZS, Hadas A. Inpatient treatment has no impact on the core thoughts and perceptions in adolescents with anorexia nervosa. Early Interv Psychiatry. 2017;11:200-7. https://doi.org/10.1111/eip.12234.

59. Naab S, Schlegl S, Korte A, Heuser J, Fumi M, Fichter M, et al. Effectiveness of a multimodal inpatient treatment for adolescents with anorexia nervosa in comparison with adults: an analysis of a specialized inpatient setting. Eat Weight Disord. 2013;18(2):167-73. https://doi.org/10.1007/ s40519-013-0029-8.

60. Schlegl S, Diedrich A, Neumayr C, Fumi M, Naab S, Voderholzer U. Inpatient treatment for adolescents with anorexia nervosa: clinical significance and predictors of treatment outcome. Eur Eat Disord Rev. 2016;24(3):214-22. https://doi.org/10.1002/erv.2416.

61. Fischer S, Peterson C. Dialectical behavior therapy for adolescent binge eating, purging, suicidal behavior, and non-suicidal self-injury: a pilot study. Psychotherapy. 2015;52(1):78. https://doi.org/10.1037/a0036065.

62. Accurso EC, Astrachan-Fletcher E, O'Brien S, McClanahan SF, Le Grange D. Adaptation and implementation of family-based treatment enhanced with dialectical behavior therapy skills for anorexia nervosa in community-based specialist clinics. Eat Disord. 2018;26(2):149-63. https://doi. org/10.1080/10640266.2017.1330319.

63. Murray SB, Anderson LK, Cusack A, Nakamura T, Rockwell R, Griffiths S, et al. Integrating family-based treatment and dialectical behavior therapy for adolescent bulimia nervosa: preliminary outcomes of an open pilot trial. Eat Disord. 2015;23(4):336-44. https://doi.org/10.1080/10640266. 2015.1044345.

64. Burton ET, Kamody RC, Pluhar El, Gray E, Abdullah S. Radical acceptance and obesity-related health conditions: a case report. J Clin Psychol Med Settings. 2020;2020(27):217-25. https://doi.org/10.1007/ s10880-019-09696-2.
65. Kamody RC, Thurston IB, Pluhar El, Han JC, Burton ET. Implementing a condensed dialectical behavior therapy skills group for binge-eating behaviors in adolescents. Eat Weight Disord. 2019;24(2):367-72. https:// doi.org/10.1007/s40519-018-0580-4

66. Safer DL, Couturier JL, Lock J. Dialectical behavior therapy modified for adolescent binge eating disorder: a case report. Cogn Behav Pract. 2007;14(2):157-67. https://doi.org/10.1016/j.cbpra.2006.06.001.

67. Kamody RC, Thurston IB, Burton ET. Acceptance-based skill acquisition and cognitive reappraisal in a culturally responsive treatment for binge eating in adolescence. Eat Disord. 2020;28(2):184-201. https://doi.org/10. 1080/10640266.2020.1731055.

68. Peterson CM, Van Diest AM, Mara CA, Matthews A. Dialectical behavioral therapy skills group as an adjunct to family-based therapy in adolescents with restrictive eating disorders. Eat Disord. 2020;28(1):67-79. https://doi. org/10.1080/10640266.2019.1568101.

69. Salbach-Andrae H, Bohnekamp I, Pfeiffer E, Lehmkuhl U, Miller AL. Dialectical behavior therapy of anorexia and bulimia nervosa among adolescents: a case series. Cogn Behav Pract. 2008;15(4):415-25. https:// doi.org/10.1016/j.cbpra.2008.04.001.

70. Mazzeo SE, Lydecker J, Harney M, Palmberg AA, Kelly NR, Gow RW, et al. Development and preliminary effectiveness of an innovative treatment for binge eating in racially diverse adolescent girls. Eat Behav. 2016;22:199-205. https://doi.org/10.1016/j.eatbeh.2016.06.014.

71. Lock J, Le Grange D, Agras WS, Fitzpatrick KK, Jo B, Accurso EC, et al. Can adaptive treatment improve outcomes in family-based therapy for adolescents with anorexia nervosa? Feasibility and treatment effects of a multi-site treatment study. Behav Res Ther. 2015;73:90-5. https://doi.org/ 10.1016/j.brat.2015.07.015.

72. Arcelus J, Fernández-Aranda F, Bouman WP. Eating disorders and disordered eating in the LGBTQ population. In: Anderson LK, Murray SB, Kaye WH, editors. Clinical handbook of complex and atypical eating disorders. Oxford University Press; 2018. p. 327-43.

73. Dohm FA, Brown M, Cachelin FM, Striegel-Moore RH. Ethnicity, disordered eating, and body image. In: Landrine H, Russo NF, editors. Handbook of diversity in feminist psychology. Springer; 2010. p. 285-309.

74. Raevuori A, Keski-Rahkonen A, Hoek HW. A review of eating disorders in males. Curr Opin Psychiatry. 2014;27(6):426-30. https://doi.org/10.1097/ YCO.0000000000000113.

75. Khalsa SS, Portnoff LC, MCCurdy-McKinnon D, Feusner JD. What happens after treatment? A systematic review of relapse, remission, and recovery in anorexia nervosa. J Eat Disord. 2017;5:20.

76. Quadflieg N, Fichter MM. Long-term outcome of inpatients with bulimia nervosa-results from the Christina Barz Study. Int J Eat Disord. 2019;52(7):834-45. https://doi.org/10.1002/eat.23084.

77. Cibich M, Wade TC. Treating bulimia nervosa in the context of gender dysphoria using 10-session cognitive behavior therapy. Int J Eat Disord. 2019;52:602-6. https://doi.org/10.1002/eat.23068.

78. Cowdrey FA, Davis J. Response to enhanced cognitive behavioural therapy in an adolescent with anorexia nervosa. Behav Cogn Psychother. 2016;44:717-22. https://doi.org/10.1017/S1352465815000740.

79. Craig M, Waine J, Wilson S, Waller G. Optimizing treatment outcomes in adolescents with eating disorders: the potential role of cognitive behavioral therapy. Int J Eat Disord. 2019;52:538-42. https://doi.org/10.1002/ eat.23067.

80. Gorrell S, Kinasz K, Hail L, Bruett L, Forsberg S, Lock J, Le Grange D. Rituals and preoccupations associated with bulimia nervosa in adolescents: does motivation to change matter? Eur Eat Disord Rev. 2019;27(3):323-8. https://doi.org/10.1002/erv.2664.

81. Gowers SG, Smyth B. The impact of a motivational assessment interview on initial response to treatment in adolescent anorexia nervosa. Eur Eat Disord Rev. 2004;12:87-93. https://doi.org/10.1002/erv.555.

82. Gowers SG, Clark A, Roberts C, Griffiths A, Edwards V, Smethurst N, et al. Clinical effectiveness of treatment for anorexia nervosa in adolescents. $\mathrm{Br}$ J Psychiatry. 2007;2007(191):427-35. https://doi.org/10.1192/bjp.bp.107. 036764.

83. Hurst $\mathrm{K}$, Read $\mathrm{S}$, Tiegan H. Bulimia nervosa in adolescents: a new frontier. Fam Ther. 2017;39:563-79. https://doi.org/10.1111/1467-6427.12095.

84. Matheson BE, Gorrell S, Bohon C, Agras WS, Le Grange D, Lock J. Investigating early response to treatment in a multi-site study for adolescent 
bulimia nervosa. Front Psychiatry. 2020;11:92. https://doi.org/10.3389/ fpsyt.2020.00092.

85. Ohmann S, Popow C, Wurzer M, Karwautz A, Sackl-Pammer P, Schuch B. Emotional aspects of anorexia nervosa: results of prospective naturalistic cognitive behavioral group therapy. Neuropsychiatrie. 2013;27(3):119-28. https://doi.org/10.1007/s40211-013-0065-7.

86. Schapman-Williams AM, Lock J. Using cognitive-behavioral therapy to treat adolescent-onset bulimia nervosa: a case study. Clin Case Stud. 2007:6(6):508-24. https://doi.org/10.1177/1534650107296822.
87. Sysko R, Hildebrandt T. Enhanced cognitive behavioural therapy for an adolescent with purging disorder: a case report. Eur Eat Disord Rev. 2011;19(1):37-45. https://doi.org/10.1002/erv.1044.

\section{Publisher's Note}

Springer Nature remains neutral with regard to jurisdictional claims in published maps and institutional affiliations.
Ready to submit your research? Choose BMC and benefit from:

- fast, convenient online submission

- thorough peer review by experienced researchers in your field

- rapid publication on acceptance

- support for research data, including large and complex data types

- gold Open Access which fosters wider collaboration and increased citations

- maximum visibility for your research: over $100 \mathrm{M}$ website views per year

At BMC, research is always in progress.

Learn more biomedcentral.com/submissions 